\title{
SYNTHESIS AND BIOLOGICAL EVALUATION OF SOME NEW CLASS OF CHROMENOIMIDAZOLE DERIVATIVES AS PROBABLE ANTI CANCER AGENTS
}

\author{
Relangi Siva Subrahmanyam ${ }^{1}$, Pattipati Ramesh $^{1}$, B.S. Krishna ${ }^{2}$, Shanti \\ Swaroop $D^{3}$, Mohammad Ashrafuddin Khan ${ }^{3}$, Mark M Darla ${ }^{3}$, Adeppa K ${ }^{3}$, \\ Baki Vijaya Bhaskar ${ }^{4}$, Wudayagiri Rajendra ${ }^{4}$ and Venkateswara Rao Anna, ${ }^{1, *}$ \\ ${ }^{1}$ Dept of Chemistry-K L University.Guntur. 522502, Andhra Pradesh, India. \\ ${ }^{2}$ Dept of Chemistry-SV University,Tirupathi.517502 Andhra Pradesh, India \\ ${ }^{3}$ Elmark Labs Pvt.Ltd. Hyderabad. TS. India \\ ${ }^{4}$ Division of Molecular Biology, Department of Zoology, SV University.Tirupathi. 517502, \\ Andhra Pradesh, India. \\ *E-mail: chem2005.venkat@gmail.com
}

\begin{abstract}
A new series of compounds with benzimidazole moiety fused pyran ring derivatives were prepared by a simple chemical methodology. Here we have designed and reported a one pot condensation of 6-hydroxy-5-formyl benzimidazole with different $\mathrm{N}$ substituted cyano acetamide derivatives to get novel chromeno-benzimidazole molecules which were characterized by different analytical tools and docking study of these compounds against a lung cancer target protein(PDB Id : 3POZ). Most of the compounds exhibited good potency in inhibiting the cancer protein.
\end{abstract}

Keywords: Chromenes, docking study, benzimidazole, epidermal growth factor receptor (EGFR), cyanoacetamides.

(C) RASĀYAN. All rights reserved

\section{INTRODUCTION}

Benzimidazole is a heterocyclic aromatic organic compound serves as an important pharmacophore in drug discovery which is being the subject of interest in medicinal chemistry and are significant subunits for development of molecules with pharmaceutical or biological application. Benzimidazole derivatives optimized based on their structures can give efficient drugs like antimicrobial, antiproliferative, antiinflammatory, antidiabetic, spasmolytic, antihypertensive and antiviral. ${ }^{1}$ Optimization of benzimidazole derivatives based on their structures has resulted in various potent drugs that are now being currently practiced in the market, like albendazole, omeprazole, mebendazole etc. ${ }^{2,3}$ Benzimidazole scaffold is known to specifically inhibit human DNA topoisomerase I. ${ }^{4,5}$ Bioisosterism of substituted benzimidazole facilitate their interaction to biopolymers such as proteins, enzymes and receptors for better activity with low toxic. ${ }^{6}$

Structurally substituted benzimidazole nucleus is significant in drug development. -NH group on benzimidazole is strongly acidic and also weak base. ${ }^{7}$ Unsubstituted -NH group in benzimidazole nucleus has phototropic tautomerism facilitating equilibrium mixtures of asymmetrically substituted compounds. Benzimidazoles can form salts. Benzimidazoles fused with different heterocyclic ring system provide a lead candidate for anticancer activity thus leading to future discovery. ${ }^{8}$ Benzimidazole derivatives substituted at 1 and 2 positions exhibit potent antioxidant activity. Moreover 1,2-substituted benzimidazole derivatives as proton pump-inhibitors have shown gastro protective action. ${ }^{9}$ 2-substituted benzimidazoles exhibited antitumor activity against human hepatocellular carcinoma (HEPG2), human breast adrenocarcinoma (MCF7) and human colon carcinoma (HCT 116) cell lines. ${ }^{10}$ Substitution at 
positions 4,5,6,7 shows inhibitory activity against protein kinase rhCK2 $\alpha$ catalytic subunit and cytotoxicity against two human cancer cell lines.${ }^{11}$

Various substituents around the benzimidazole nucleus have provided a wide spectrum of biological activities. Owing to the importance of substituents at various positions here we are reporting novel substituent's of pyrano fused bezimadazole ring derivatives as potential anti-cancer agents. Both pyrones and benzimidazoles possess a wide range of biological activities ranging from simple anti microbial activity to high-risk anti cancer activity. This work is intended to design a new series of novel heterocyclic compounds, which were synthesized, characterized and carried out docking study on anti cancer target protein.

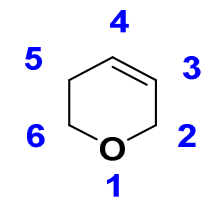

3,6-dihydro-2H-pyran

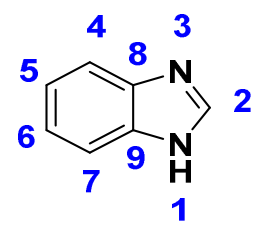

1H-benzo[d]imidazole

Fig.-1: Basic structures of Pyran and Benzimidazole

Initially, Benzimidazoles class of compounds were used for the anthelmintic activity, later their activity was widely studied and found that they possess a broad range of biological activity. Benzimidazole derivatives such as Albendazole, Fenbendazole, Mebendazole and Oxfendazole are also effective against non-gastrointestinal roundworms in the lungs, kidneys, skin, etc., based on composite and dose. ${ }^{12}$ Other than its activity in human, benzimidazole nucleus is also used in agriculture to control pests as a fungicide and as veterinary anthelmintics. ${ }^{13,14}$ 2-substituted benzimidazoles are pharmacologically more potent antibacterial agents. ${ }^{15}$ Presence of amidino moiety on benzimidazole nucleus possess antimicrobial and anti protozoal activity. ${ }^{16}$ Aryl or alkyl carboxamide benzimidazole derivatives possess potent antihypertensive activity by inhibiting angiotensine II. ${ }^{17}$ Nitro benzimidazoles were reported to possess antitumor activity. ${ }^{18}$ Substitution of carboxylic acid at 2 positions is a dominant structural requirement for anti inflammatory activity. ${ }^{19}$ Domperidone is an anti-emitic drug which contains two benzimidazole moieties.

Benzimidazole derivatives possess antibacterial activity by inhibiting topoisomerase I and topoisomerase II. ${ }^{20}$ Antiemetic effect is by blocking Dopamine receptors at both the chemoreceptor trigger zone and at the gastric level. Anthelmentic activity is exerted by depleting parasites glycogen stores through degenerative alterations in intestinal cells of the worm by binding to the colchicine-sensitive site of tubulin, thus inhibiting its polymerization into microtubules. ${ }^{21}$ The antihypertensive effect of benzimidazole nucleus Angiotensin I receptor antagonism. ${ }^{22}$ Anti tumor activity is by inhibition of the catalytic activity of many enzymes involved in DNA synthesis. ${ }^{23}$

Existing benzimidazole derivatives have a common sulfide linkage susceptible to oxidation and forms two metabolites sulphoxide and sulphone possesses carbonyl functional groups that may be reduced to form alcohols. All of these drugs possess carbamate groups that can be hydrolyzed to form aminobenzimidazoles.

\section{Introduction of target protein}

Epidermal growth factor receptor (EGFR), a growth-factor-receptor tyrosine kinase. EGFR belongs to a human ErbB protein family, which contains a cytoplasmic tyrosine kinase region and this family consists 
RASĀYAN J. Chem.

Vol. 10 | No. 4 |1194-1212 | October - December | 2017

of EGFR (ErbB1), HER2 (ErbB2, HER2/neu), HER3 (ErbB3) and HER4 (ErbB4). Epidermal growth factor binds to the specific receptor located on different cells EGFR mediated biological activities include increased amino acid transport, increased glucose uptake and growth. ${ }^{24,25}$ High levels of EGFR, its cognate ligands are commonly identified in multiple cancer types. After binding of EGF to the receptor dimerizes, either as a homodimer or as a heterodimer preferentially with undergoes autophosphorylation at specific tyrosine residues within the intracellular domain these in turn activates downstream signaling pathways, including the Ras/Raf/mitogen-activated protein kinase (MAPK) pathway and the phosphatidylinositol 3'-kinase (PI3K)-Akt pathway. ${ }^{26}$ EGFR is overexpressed in many solid tumors, including lung, head and neck, breast, kidney, colon, ovary, prostate, brain and bladder cancer. Human epidermal growth factor 2(HER2) is known to be the preferred binding partner of EGFR and the HER2/EGFR heterodimer shows an increased signaling potency compared to EGFR homodimers. ${ }^{27}$

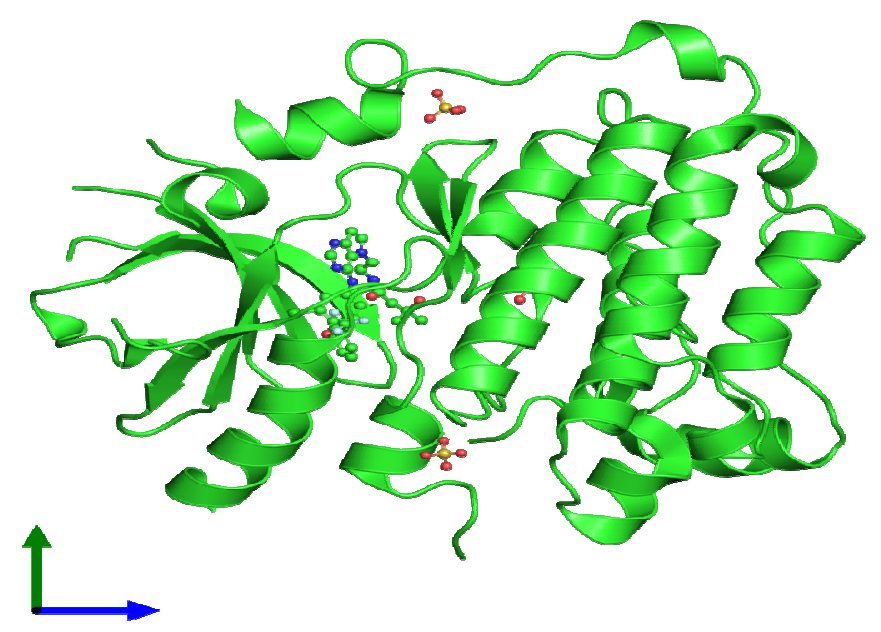

Fig.-2: Structure 3POZ protein visualized using pyMol

These transmembrane proteins are activated through binding by peptide growth factors of the EGF-family of proteins. Overexpression of EGFR, EGF-like peptides, mutations of the EGFR tyrosine kinase domain are often reported in human carcinomas and in vivo and in vitro studies have shown that these proteins are able to induce cell transformation. Genetic alterations of the EGFR are correlated with high probability to respond to anti-EGFR agents. However, ErbB proteins and their ligands form a complex system in which the interactions occurring between receptors and ligands affect the type and duration of the intracellular signals that derive from receptor activation. ${ }^{28}$

Many EGF-containing molecules, including human epidermal growth factor receptor family (HER tyrosine kinase receptor) ligands such as EGF and TGF- $\alpha$, are shed from the surface by extracellular proteases, resulting in longer range extracellular signaling. ${ }^{29}$

EGF receptor (EGFr) are closely related to ErbB2 and associated with a more aggressive clinical behavior. Further, transfection or activation of high levels of these two receptors in nonmalignant cell lines can lead to a transformed phenotype. For these reasons, EGFR inhibitors directed at preventing the function of these receptors have the potential to be useful for EGF treatment in cancer. ${ }^{30}$

A series of phase III studies with these antibodies and direct tyrosine kinase inhibitors are ongoing and will further address the role of these active anti-receptor agents in the treatment of patients with cancer ${ }^{31}$

EGFR activation via ligand binding results in signaling through various pathways ultimately resulting in cellular proliferation, survival, angiogenesis, invasion and metastasis. Aberrant expression or activity of EGFR has been strongly linked to the etiology of several human epithelial cancers including but not limited to head and neck squamous cell carcinoma (HNSCC), non-small cell lung cancer (NSCLC), colorectal cancer (CRC), breast cancer, pancreatic cancer and brain cancer. Thus intense efforts have been made to inhibit the activity of EGFR by designing antibodies against the ligand binding domains 
(cetuximab and panitumumab) or small molecules against the tyrosine kinase domain (Erlotinib, Gefitinib and Lapatinib). Although targeting membrane-bound EGFR has shown benefit, a new and emerging role for EGFR is now being elucidated. ${ }^{32}$ The $3 \mathrm{POZ}$ has $37.3 \mathrm{KDa}$, its domain contains 327 amino acids of single chain glycoproteins. The domain also consists of two $\beta$-sheets, usually referred to as the major $(\mathrm{N}$ terminal) and minor (C-terminal) sheets. It is primarily stabilized by three disulfides with disulfide connectivity ababcc. EGF domain. The half-cystines of the abc motif are arranged in a triangle on the major sheet and binding to its membrane receptor activates a cyclic nucleotide-independent, tyrosinespecific, protein kinase. ${ }^{33}$

Specific molecular targeted therapy has ameliorated the treatment of breast cancer. Drugs like Trastuzumab and Lapatinib acting by inhibiting human epidermal growth factor receptor-2 (HER2) or epidermal growth factor receptor (EGFR) has limited effect on brain metastasis due to poor penetration through the blood-brain barrier and their removal from the central nervous system (CNS) by the pglycoprotein (Pgp) drug efflux pump. TAK-285 is a novel small molecule pyrrolo [3, 2-d] pyrimidinederivative with the mechanism of action of inhibiting dual EGFR/HER2 thus exhibiting antitumor activity against cancers expressing HER2 or EGFR. Tak-285 has an advantage of penetrating the CNS and also similar inhibitory efficacy to Lapatinib. TAK-285 is distributed more efficiently to brain tissues than other HER2-targeted agents. TAK-285 $400 \mathrm{mg}$ BID appears to be well tolerated. Absorption was fast and exposure increased dose-dependently. 3POZ is the protein database ID for the crystal structure of active EGFR kinase domain which gave insight into the mechanism of HER2 and EGFR inhibition and may help guide the design and development of new cancer drugs. Enzyme inhibitory activity of the cytoplasmic domain of ErbB kinases was evaluated by phosphorylation of a peptide substrate. TAK-285 low nanomolar pyrrolo [3, 2-d] pyrimidine-based inhibitors of both HER2 and EGFR. The in-vitro potency of TAK-285 against HER2 and EGFR is similar. In ATP competition assays, both compounds were shown to bind to the respective kinase in an ATP-competitive manner. ${ }^{34}$

The other ring nitrogen atom makes a water-mediated hydrogen bond to Thr854. The bulky 3trifluoromethylphenyl group occupies a pocket formed by Met766, Cys775, Leu777, Leu788, Thr790, Thr854 and Phe856. The terminal tri fluoro methyl phenyl group is rotated $150^{\circ}$ from its position in the EGFRTAK-285 complex and packs against-helix C, making hydrophobic contact with the side chains of Thr862, Glu770, Met774, Ser783, Leu785, Leu790, Leu796 and Phe864. ${ }^{35}$

\section{General}

\section{EXPERIMENTAL}

All the chemicals were purchased from SD Fine Chem, India. Melting points were determined on a Creative digital Melting point apparatus and are uncorrected. Thin layer chromatography for completion of the reaction and column purification was performed on silica gel coated plates from Macherey-NagelGermany, which were visualized by UV light and ninhydrin spray. FT-IR spectra were recorded on Bucker Alpha-T.1H and ${ }^{13} \mathrm{C}$ NMR (proton decoupled) spectra were recorded on a Varian $400 \mathrm{MHz}$ spectrometer using DMSO- $\mathrm{d}_{6}$ and $\mathrm{CDCl}_{3}$ as a solvent. Mass spectra were recorded on an Agilent triple quadrapole mass spectrometer equipped with a turbo ion spray interface at $360^{\circ} \mathrm{C}$. Elemental analyses were performed using EA 1112 Thermo Finnigan instrument.

\section{Synthetic procedure for the designed compounds (3a-t)}

This procedure consists of two stages

1. 6-hydroxy benzimidazole is initially formylated under Duff's conditions to form a 6-hydroxy-5formyl benzimidazole (1).

2. Preparation of $\mathbf{N}$-substituted cyano acetamide derivatives (2a-t) and its condensation with compound (1) to form the desired novel pyrano benzimidazoles (3a-t). 


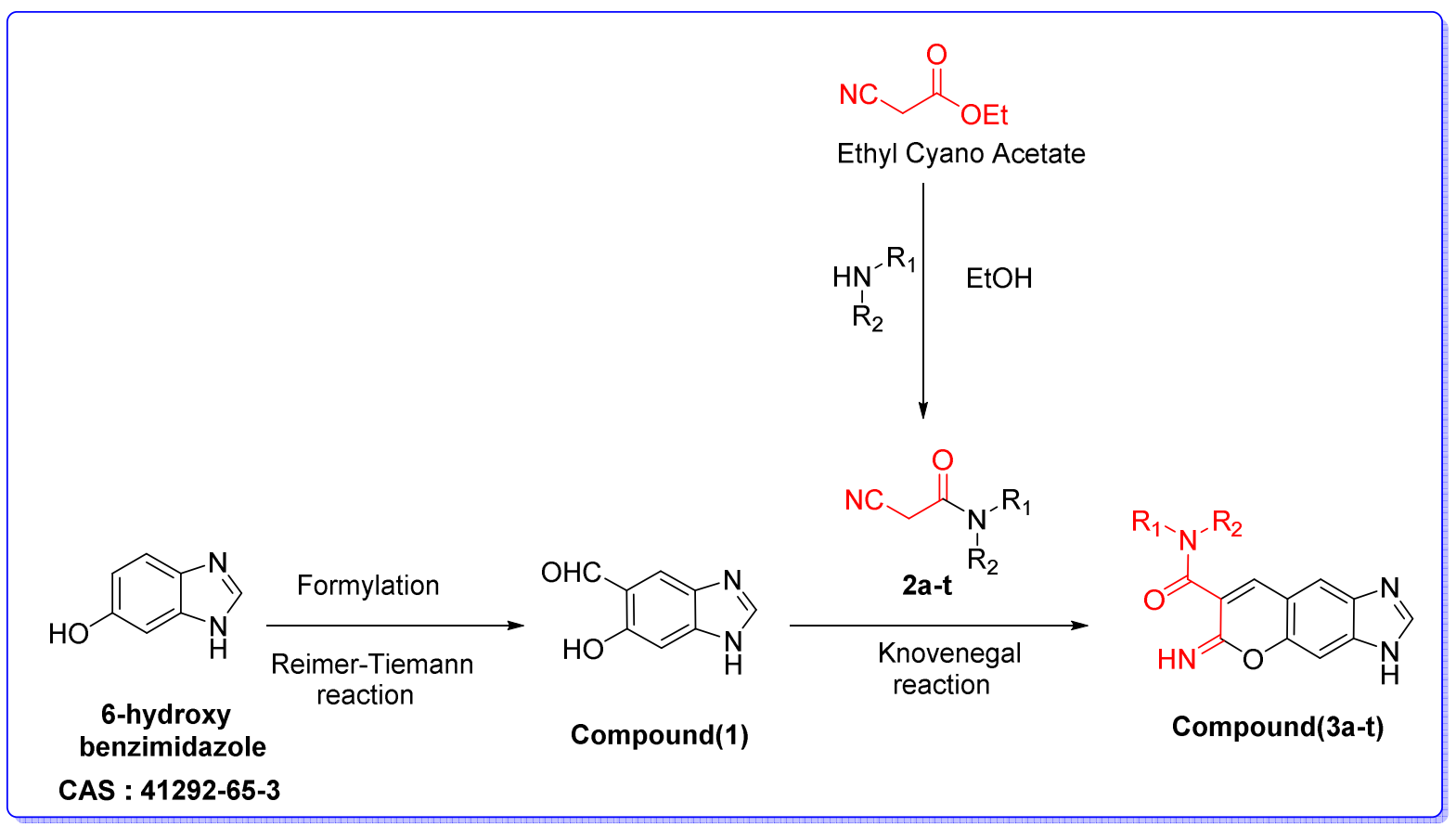

Scheme-1: Chemical path for the synthesis of desired compounds (3a-t)

Preparation of 6-hydroxy-7-formyl benzimidazole $(\mathbf{1})^{36,37}$

6-hydroxy benzimidazole (20 g, $0.1490 \mathrm{~mol}$.) was dissolved in $200 \mathrm{ml}$ ethanol, $4.5 \mathrm{~g}, 0.1125 \mathrm{~mol}$. of 5\% sodium hydroxide solution was added to the Reaction mixture. The reaction mixture was heated to 80 $83^{\circ} \mathrm{C}$. $35 \mathrm{~g}, 0.0 .2928 \mathrm{~mol}$. of chloroform was added drop-wise over a period of $30 \mathrm{~min}$. The reaction mixture was maintained at reflux for $1.0 \mathrm{~h}$, the reaction mixture was cooled to room temperature. The solvents were removed by vacuum distillation below $50^{\circ} \mathrm{C}$. The obtained crude compound was acidified with $1 \mathrm{M} \mathrm{HCl}$ to $\mathrm{pH} 2-3$. The product was extracted with Di ethyl ether $(3 \times 100 \mathrm{~mL})$. The combined ether layer was dried over anhydride sodium sulfate. Distilled off the solvent and a pale yellow solid (compound 1) was isolated (10.8 g), theoretical yield $45 \%$.

\section{Preparation of N-Substituted Cyano Acetamide Derivatives (2a-t) $)^{38,39,40}$}

In a $20 \mathrm{~mL}$ RB flask equipped with reflux condenser, thermo socket, magnetic stirrer and addition funnel, ethyl-2-cyano acetate $(1.0 \mathrm{~g}, 0.0088 \mathrm{~mol})$ is mixed with benzyl amine $(1.13 \mathrm{~g}, 0.0106 \mathrm{~mol})$ in $10 \mathrm{ml}$ ethanol medium under reflux for $1.0 \mathrm{hr}$. The reaction mixture was cooled to room temperature. The isolated solid was separated by filtration. An off white solid $(0.9 \mathrm{~g})$ of N-benzyl cyanoacetamide $(2 \mathrm{~m})$ was obtained after drying (65\% theoretical yield). These compounds were directly used in the next step. The schematic path was shown below. A similar procedure was repeated for the other analogs. The different amines used for the scheme has been shown in Table-1.

General procedure for preparation of chromeno imidazole derivatives $(\mathbf{3 a - t})^{41,42}$ Compound $\mathbf{1}, 0.5$ $\mathrm{g}(0.0030 \mathrm{~mol})$ was dissolved in $5.0 \mathrm{ml}$ absolute ethanol, to this a drop of piperidine added along with $\mathrm{N}$ benzyl cyano acetatamide $(2 \mathrm{~m}), 0.65 \mathrm{~g}(0.0037 \mathrm{~mol})$. The reaction mixture was heated to reflux, maintained under reflux for $2 \mathrm{~h}$.

The completion of the reaction was monitored by TLC by the absence of compound 2 . The reaction mixture was cooled to $45^{\circ} \mathrm{C}$ and ethanol was distilled off under vacuum below $50{ }^{\circ} \mathrm{C}$. After removing 70 $\%$ of ethanol, it was cooled to below $5{ }^{\circ} \mathrm{C}$. An off white solid $(\mathbf{3 m})(0.73 \mathrm{~g})$ was formed which was separated by filtration. The yield was $75 \%$ (based on theoretical yield). A similar procedure was repeated for the other analogs. 
RASĀYAN $J$. Chem.

Vol. 10 | No. 4 |1194-1212 | October - December | 2017

Table-1: List of different amines used for synthesis of cyanoacetamide derivatives (2a-t)

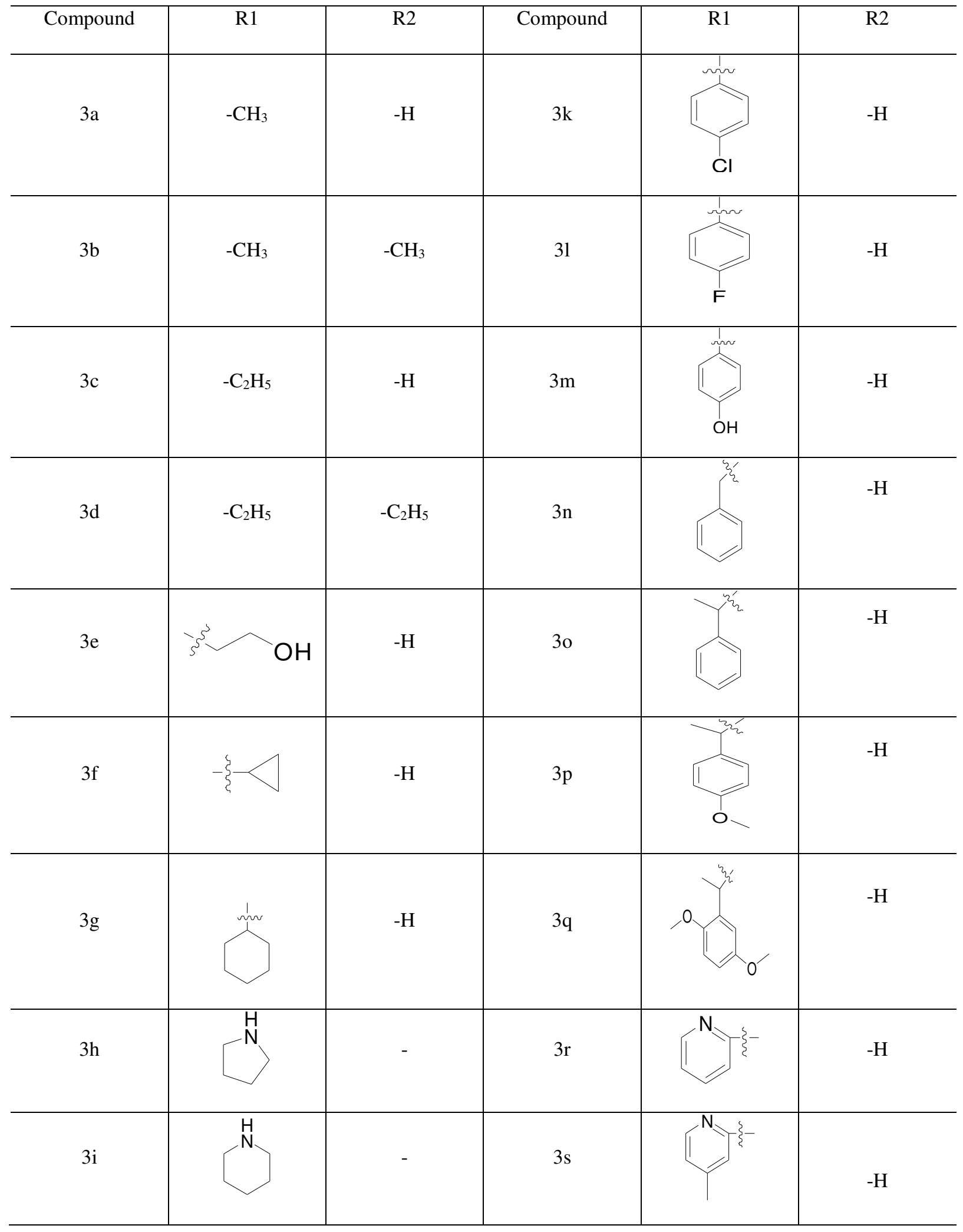


RASĀYAN $J$. Chem.

Vol. 10 | No. 4 |1194-1212 | October - December | 2017

\begin{tabular}{l|l|l|l|l|l}
\hline $3 \mathrm{j}$ & $\mathrm{H}$ & $3 \mathrm{t}$ & \\
\hline
\end{tabular}

\section{Molecular docking simulation}

All the ligand molecules were uploaded into the Open Babel module of AUTODOCK VINA 4.0 with PyRx interface and energy minimized with UFF force field using a conjugate-gradient algorithm with 200 run iterations and converted into pdbqt format. NorA model was uploaded and converted into pdbqt format. Virtual screening was carried out with all the compounds against NorA efflux pump by using the Lamarkian genetic algorithm. Docking parameters were set as 150 Number of the individual population, 25000 Max no. of energy evaluation, 27000 Max no of generation, Top individuals to survive to next generation is 1 , Gene mutation rate of 0.02 , a Crossover rate of 0.8 , Cauchy beta of 1.0 and GA window size is 10.0. The grid was set to binding pocket at $X=29.3901, Y=-42.745, Z=-51.82$ and dimensions $(\AA)$ at $\mathrm{X}=90.000, \mathrm{Y}=105.7097, \mathrm{Z}=104.2448$ and exhaustiveness 8 . The best-docked ligand conformations were saved and assessed the binding energies and binding affinities, bond angle, lengths, hydrogen bonding interactions using MOE and PyMol.

\section{Born interaction energies and binding affinities}

To explore the potential diverse lead molecules, binding affinities between hits-LpxA complexes were determined using Born-volume integral (GB/VI) implicit solvent methods implemented in MOE. Non bonded interactions between hit and protein complex include Vander Waals, Coulomb electrostatic interactions and implement solvent interactions are termed as born interaction energy. The strain energies of ligand and protein and solvent molecules were ignored during binding affinities estimations. The calculated binding affinity using London scoring method represented in $\mathrm{Kcal} / \mathrm{mol}$ unit. Ligand binding pocket residues and ligand molecules were kept flexible while excluding binding pocket was kept rigid to tether restraints to discourage gross movements. Energy minimization of protein-ligand complexes was carried out before calculating binding affinities.

\section{RESULTS AND DISCUSSION}

Ethyl cyano acetate $(1.0 \mathrm{eq})$ was condensed with different amines (1.1 eq) in ethanol under reflux to get various $\mathrm{N}$-substituted cyano acetamides (2a-t). All the reactions were given good yields varies between 55-75\% theoretically. All the cyanoacetamide derivatives were isolated as solid and with put purification used in the final step. The physical and spectral parameters were compared with authentic compounds. Formylation of compound 1 was tried out in different methodologies like Duff's ${ }^{43}$, 44, Reimar -Thiemann and Villsmayer ${ }^{45}$ conditions. Both Duff's, reaction resulted in decomposed products. Reimar -Thiemann reactions conditions was conceded successful formylated compound. This was reconfirmed by proton NMR and IR spectrum with a singlet at de-shielded zone $\delta 10.5$ and stretching aldehyde band at $1750 \mathrm{~cm}^{-1}$ respectively.

The chemical structures of these final compounds were established using spectroscopic methods including IR, ${ }^{1} \mathrm{H}$ and ${ }^{13} \mathrm{C}-\mathrm{NMR}$, and HR-MS. Elemental analyses established the composition which was further confirmed by high-resolution ESI(+) MS spectral analysis. The percent abundance coincides with the respective molecular ion peaks. Since the IR spectra of all the compounds were quite similar therefore discussion is confined to the important vibrations only. The carbonyl stretching frequency of chromene moiety varies from 1644-1729 $\mathrm{cm}^{-1}$. A band in the range of $1546-1594 \mathrm{~cm}^{-1}$ was assigned to the stretching frequency of $\mathrm{C}=\mathrm{C}$ bond. The IR spectra of these amides showed the $-\mathrm{C}-\mathrm{O}$ absorption peaks around $1110-1200 \mathrm{~cm}^{-1}$. The IR spectra showed $-\mathrm{N}-\mathrm{C}$ stretching band at the range of $3200-3342 \mathrm{~cm}^{-1}$. The weak shielded signals suggest that $-\mathrm{NH}$ protons are most probably involved in hydrogen bond formation. In addition, a pair of cis coupled doublets of $-\mathrm{C}=\mathrm{C}$ - unsaturated protons at were observed at $\delta$ 6.0-6.8 and 7.5-7.8 ppm and assigned for $\mathrm{H}-3$ and $\mathrm{H}-4$ protons in ${ }^{1} \mathrm{H}-\mathrm{NMR}$ which is characteristic for 
chromene moieties. A pair of ortho coupled doublets for an aromatic moiety of chromene was also resolved well in case of compounds where aliphatic moieties were substituted on N. Also de-shielded peaks at around $8.9 \mathrm{ppm}$ were attributed to $\mathrm{N}-\mathrm{H}$ group of the side chain. The rest of the resonances for compounds were assigned to the protons of aliphatic and aromatic ring system on ' $\mathrm{N}$ ' in acetamide side chain. The compounds were also confirmed by studying the proton decoupled ${ }^{13} \mathrm{C}-\mathrm{NMR}$ which show peaks around $\delta 116 \mathrm{ppm}$.

\section{Spectral Analysis of the final compounds}

6-imino-N-methyl-3, 6-dihydrochromeno [7,6-d] imidazole-7-carboxamide (3a)

IR $\left(\mathrm{KBr}, \mathrm{cm}^{-1}\right): 3313(-\mathrm{NH}), 1687(-\mathrm{C}=\mathrm{O}), 1634(-\mathrm{C}=\mathrm{C}), 1188(-\mathrm{C}-\mathrm{O}) .{ }^{1} \mathrm{H}$ NMR $\left(\mathrm{CDCl}_{3}\right): \delta 12.3(\mathrm{~s}, \mathrm{H},-\mathrm{NH}$, imidazole), 9.41(s, -H, $-\mathrm{N}=\mathrm{H}), 8.59(\mathrm{~s}, \mathrm{H}$, pyrane), 8.20(s, H, -CH, imidazole), 8.00(s, -NH, -CO-NH), 7.55(s, H, C-4), 7.00(s, H, C-9), 2.88(s, 3H, $\left.-\mathrm{CH}_{3}\right)^{13} \mathrm{C}$ NMR $\left(\mathrm{CDCl}_{3}\right): \delta 161(\mathrm{C}, \mathrm{C}-6), 158(\mathrm{C},-\mathrm{CO}), 150(\mathrm{C}$, C-12), 141(C, C-2), 135(C, C-11), 130(C, C-10), 125(C, C-8), 119(C, C-9),117(C, C-13), 114(C, C-7), 108(C, C-4), 30(C,-CH3).MS: $\mathrm{M}^{+}$at m/z : 243.43Anal.Calcd for $\mathrm{C}_{12} \mathrm{H}_{10} \mathrm{~N}_{4} \mathrm{O}_{2}: \mathrm{C}, 59.50 ; \mathrm{H}, 4.16 ; \mathrm{N}, 23.13$; O, 13.21, Found; C C, 60.00; H, 4.20; N, 23.10; O, 13.15

\section{6-imino-N, N-dimethyl-3, 6-dihydrochromeno [7, 6-d] imidazole-7-carboxamide (3b)}

IR $\left(\mathrm{KBr}, \mathrm{cm}^{-1}\right): 3325(-\mathrm{NH}), 1710(-\mathrm{C}=\mathrm{O}), 1676(-\mathrm{C}=\mathrm{C}), 1150(-\mathrm{C}-\mathrm{O}) .{ }^{1} \mathrm{H} \mathrm{NMR}\left(\mathrm{CDCl}_{3}\right): \delta 12.50(\mathrm{~s}, \mathrm{H},-\mathrm{NH}$, imidazole), 9.30(s,-H, -N=H), 8.50(s, H, pyrone), 8.15(s, H, -CH , imidazole), 7.30(s, H, C-4), 7.10(s, H, $\mathrm{C}-9), 3.00\left(\mathrm{~s}, 6 \mathrm{H},-2 \mathrm{xCH}_{3}\right)^{13} \mathrm{C}$ NMR $\left(\mathrm{CDCl}_{3}\right): \delta 162(\mathrm{C}, \mathrm{C}-6), 159(\mathrm{C},-\mathrm{CO}), 150(\mathrm{C}, \mathrm{C}-12), 142(\mathrm{C}, \mathrm{C}-2)$, 138(C, C-11), 128(C, C-10), 125(C, C-8), 119(C, C-9), 117(C, C-13), 114(C, C-7), 108(C, C-4), 40(2C,2xMe).MS: $\mathrm{M}^{+}$at $\mathrm{m} / \mathrm{z}: 257.40$ Anal.Calcd for $\mathrm{C}_{13} \mathrm{H}_{12} \mathrm{~N}_{4} \mathrm{O}_{2}$ : C, 60.93; H, 4.72; N, 21.86; O, 12.49, Found; C, 60.90; H, 4.70; N, 21.90; O, 12.53

\section{N-ethyl-6-imino-3, 6-dihydrochromeno [7, 6-d] imidazole-7-carboxamide (3c)}

IR $\left(\mathrm{KBr}, \mathrm{cm}^{-1}\right): 3451(-\mathrm{NH}), 1766(-\mathrm{C}=\mathrm{O}), 1628(-\mathrm{C}=\mathrm{C}), 1119(-\mathrm{C}-\mathrm{O}) .{ }^{1} \mathrm{H}$ NMR $\left(\mathrm{CDCl}_{3}\right): \delta 12.34(\mathrm{~s}, \mathrm{H},-\mathrm{NH}$, imidazole), 9.43(s, -H, -N=H), 8.45(s, H, pyrone), 8.20(s, H, -CH, imidazole), 7.25(s, H, C-4), 7.00(s, H, C-9), 3.24(q, 2H, - $\left.\mathrm{CH}_{2}\right), 1.54\left(\mathrm{t}, 3 \mathrm{H},-\mathrm{CH}_{3}\right) .{ }^{13} \mathrm{C} \mathrm{NMR}\left(\mathrm{CDCl}_{3}\right): \delta 161(\mathrm{C}, \mathrm{C}-6), 158(\mathrm{C},-\mathrm{CO}), 158(\mathrm{C}, \mathrm{C}-12)$, 157(C, C-2), 140(C, C-11), 128(C, C-10), 125(C, C-8), 120(C, C-9), 117(C, C-13),114(C, C-7), 108(C, C-4), 40(C,- $\left.\mathrm{CH}_{2}\right), 20\left(\mathrm{C},-\mathrm{CH}_{3}\right) . \mathrm{MS}: \mathrm{M}^{+}$at $\mathrm{m} / \mathrm{z}: 257.40$ Anal.Calcd for $\mathrm{C}_{13} \mathrm{H}_{12} \mathrm{~N}_{4} \mathrm{O}_{2}: \mathrm{C}, 60.93 ; \mathrm{H}, 4.72 ; \mathrm{N}$, 21.86; O, 12.49, Found; C, 61.00; H, 4.80; N, 21.75; O, 12.40

\section{N, N-diethyl-6-imino-3, 6-dihydrochromeno [7,6-d]imidazole-7-carboxamide(3d)}

IR $\left(\mathrm{KBr}, \mathrm{cm}^{-1}\right)$ : 3401(-NH), $1729(-\mathrm{C}=\mathrm{O}), 612(-\mathrm{C}=\mathrm{C}), 1095(-\mathrm{C}-\mathrm{O}) .{ }^{1} \mathrm{H}$ NMR $\left(\mathrm{CDCl}_{3}\right): \delta 12.36(\mathrm{~s}, \mathrm{H},-\mathrm{NH}$, imidazole), 9.32(s, -H, -N=H), 8.60(s, H, pyrone), 8.20(s, H, -CH, imidazole), 7.30(s, H, C-4), 7.10(s, H, $\mathrm{C}-9), 3.10\left(\mathrm{q}, 4 \mathrm{H},-2 \mathrm{xCH}_{2}\right), 1.20\left(\mathrm{t}, 6 \mathrm{H},-2 \mathrm{xCH}_{3}\right) .{ }^{13} \mathrm{C} \mathrm{NMR}\left(\mathrm{CDCl}_{3}\right): \delta 165(\mathrm{C}, \mathrm{C}-6), 160(\mathrm{C},-\mathrm{CO}), 158(\mathrm{C}$, C-12), 155(C, C-2), 142(C, C-11), 130(C, C-10), 124(C, C-8), 118(C, C-9), 116(C, C-13),114(C, C-7), $110(\mathrm{C}, \mathrm{C}-4), 44\left(2 \mathrm{C},-2 \mathrm{xCH}_{2}\right), 15\left(2 \mathrm{C},-2 \mathrm{xCH}_{3}\right) . \mathrm{MS}: \mathrm{M}^{+}$at $\mathrm{m} / \mathrm{z}: 285.40$ Anal.Calcd for $\mathrm{C}_{15} \mathrm{H}_{16} \mathrm{~N}_{4} \mathrm{O}_{2}: \mathrm{C}$, 63.37; H, 5.67; N, 19.71; O, 11.25, Found; C, 63.44; H, 5.70; N, 19.68; O, 11.20

\section{N-(2-hydroxyethyl)-6-imino-3, 6-dihydrochromeno [7, 6-d]imidazole-7-carboxamide(3e)}

IR $\left(\mathrm{KBr}, \mathrm{cm}^{-1}\right)$ : 3550(-OH), 3450(-NH), $1758(-\mathrm{C}=\mathrm{O}), 1575(-\mathrm{C}=\mathrm{C}), 1088(-\mathrm{C}-\mathrm{O}) .{ }^{1} \mathrm{H}$ NMR $\left(\mathrm{CDCl}_{3}\right): \delta$ 11.80 (s, H, -NH, imidazole), 9.40(s, -H, -N=H), 8.65(s, H, pyrone), 8.25(s , H, -CH, imidazole), 7.33(s, $\mathrm{H}, \mathrm{C}-4), 7.00(\mathrm{~s}, \mathrm{H}, \mathrm{C}-9), 5.00(\mathrm{~s}, \mathrm{H},-\mathrm{OH}), 4.00\left(\mathrm{t}, 2 \mathrm{H},-\mathrm{CH}_{2}-\mathrm{OH}\right), 3.44\left(\mathrm{t}, 2 \mathrm{H},-\mathrm{CH}_{2}-\mathrm{NH}\right)^{13} \mathrm{C} \mathrm{NMR}\left(\mathrm{CDCl}_{3}\right)$ : $\delta$ 162(C, C-6), 160 (C, -CO), 157(C, C-12), 152(C, C-2), 145(C, C-11), 132(C, C-10), 122(C, C-8), 117(C, C-9), 114(C, C-13), 111(C, C-7), 108(C, C-4), 62(C,-CH $-\mathrm{OH}), 40\left(\mathrm{C},-\mathrm{CH}_{2}-\mathrm{NH}\right) . \mathrm{MS}: \mathrm{M}^{+}$at m/z :273.25.Anal.Calcd for $\mathrm{C}_{13} \mathrm{H}_{12} \mathrm{~N}_{4} \mathrm{O}_{3}$ : C, 57.35; H, 4.44; N, 20.58; O, 17.63, Found; C, 57.40; H, 4.45; N, $20.62 ; \mathrm{O}, 17.50$ 


\section{RASĀYAN J. Chem.}

Vol. 10 | No. 4 |1194-1212 | October - December | 2017

N-cyclopropyl-6-imino-3,6-dihydrochromeno[7,6-d]imidazole-7-carboxamide(3f)

IR $\left(\mathrm{KBr}, \mathrm{cm}^{-1}\right): 3500(-\mathrm{NH}), 1758(-\mathrm{C}=\mathrm{O}), 1575(-\mathrm{C}=\mathrm{C}), 1088(-\mathrm{C}-\mathrm{O}) .{ }^{1} \mathrm{H}$ NMR $\left(\mathrm{CDCl}_{3}\right): \delta 11.95(\mathrm{~s}, \mathrm{H},-$ $\mathrm{NH}$, imidazole), 9.25(s, -H, -N=H), 8.54(s, H, pyrone), 8.25(s, H, -CH, C-2), 7.30(s, H, C-4), 7.10(s, H, $\mathrm{C}-9), 3.00(\mathrm{~m}, \mathrm{H},-\mathrm{N}-\mathrm{CH}), 1.0-55\left(\mathrm{~m}, 4 \mathrm{H}\right.$, cyclopropyl). ${ }^{13} \mathrm{C} \mathrm{NMR}\left(\mathrm{CDCl}_{3}\right): \delta 161(\mathrm{C}, \mathrm{C}-6), 159(\mathrm{C},-\mathrm{CO})$, 155(C, C-12), 150(C, C-2), 144(C, C-11), 135(C, C-10), 120(C, C-8), 118(C, C-9), 115(C, C-13), 112(C, $\mathrm{C}-7), 107(\mathrm{C}, \mathrm{C}-4), 30(\mathrm{C},-\mathrm{CH}-\mathrm{NH}), \quad 12\left(2 \mathrm{C}\right.$, -cyclopropyl).MS: $\mathrm{M}^{+}$at $\mathrm{m} / \mathrm{z}: 269.30$ Anal.Calcd for $\mathrm{C}_{14} \mathrm{H}_{12} \mathrm{~N}_{4} \mathrm{O}_{2}$ : C, 62.68; H, 4.51; N, 20.88; O, 11.93, Found; C, 62.75; H, 4.40; N, 20.85; O, 12.00

N-cyclohexyl-6-imino-3, 6-dihydrochromeno[7,6-d] imidazole-7-carboxamide (3g)

IR $\left(\mathrm{KBr}, \mathrm{cm}^{-1}\right): 3395(-\mathrm{NH}), 1740(-\mathrm{C}=\mathrm{O}), 1622(-\mathrm{C}=\mathrm{C}), 1100(-\mathrm{C}-\mathrm{O}) .{ }^{1} \mathrm{H}$ NMR $\left(\mathrm{CDCl}_{3}\right): \delta 12.36(\mathrm{~s}, \mathrm{H},-$ $\mathrm{NH}$, imidazole), 9.50(s, -H, -N=H), 8.50(s, H,-NH), 8.40(s, H, C-8), 8.20(s, H, C-2), 7.30(s, H, C-9), 6.80(s, H, C-4), 3.5(m, H, -C-NH), 2.0(m, 4H, cylohexane $), 1.5(\mathrm{~m},-4 \mathrm{H}$, cyclohexane $), 1.2(\mathrm{~m}, 2 \mathrm{H}$, cylohexane ). ${ }^{13} \mathrm{C}$ NMR $\left(\mathrm{CDCl}_{3}\right): \delta 164(\mathrm{C},-\mathrm{CO}), 160(\mathrm{C},-\mathrm{C}=\mathrm{N}), 158(\mathrm{C}, \mathrm{C}-13), 145(\mathrm{C}, \mathrm{C}-2), 139(\mathrm{C}, \mathrm{C} 11)$, 13(C, C-10), 121(C, C-9), 119(C, C-12), 116(C, C-7), 100(C, C-4), 55(C, C'-1), 38(2C, C'-2, C'-6), 30C, $\left.\mathrm{C}^{\prime}-4\right), 24\left(2 \mathrm{C}, \mathrm{C}^{\prime}-3, \mathrm{C}^{\prime}-5\right) \mathrm{MS}: \mathrm{M}^{+}$at $\mathrm{m} / \mathrm{z}$ :311.50Anal.Calcd for $\mathrm{C}_{17} \mathrm{H}_{18} \mathrm{~N}_{4} \mathrm{O}_{2}: \mathrm{C}, 65.79 ; \mathrm{H}, 5.85 ; \mathrm{N}, 18.05$; O, 10.31, Found; C, 65.85; H, 5.90; N, 18.00; O, 10.25

(6-imino-3, 6-dihydrochromeno [7, 6-d]imidazol-7-yl)(pyrrolidin-1-yl) methanone (3h) IR $\left(\mathrm{KBr}, \mathrm{cm}^{-1}\right): 3400(-\mathrm{NH}), 1709(-\mathrm{C}=\mathrm{O}), 1612(-\mathrm{C}=\mathrm{C}), 1111(-\mathrm{C}-\mathrm{O}) .{ }^{1} \mathrm{H}$ NMR $\left(\mathrm{CDCl}_{3}\right): \delta$ 12.36(s, H, $\mathrm{NH}$, imidazole), 9.40(s, -H, -N=H), 8.70(s, H, C-8), 8.30(s, H, C-2), 7.50(s, H, C-9), 7.10(s, H, C-4), $3.50\left(\mathrm{t}, 4 \mathrm{H},-2 \mathrm{xCH}_{2}\right.$, pyrrolidine), $2.00\left(\mathrm{t}, 4 \mathrm{H},-2 \mathrm{xCH}_{2}\right.$, pyrrolidine $) .{ }^{13} \mathrm{C} \mathrm{NMR}\left(\mathrm{CDCl}_{3}\right): \delta 165(\mathrm{C}, \mathrm{CO}), 160$ $(\mathrm{C}, \mathrm{C}=\mathrm{NH}), 151(\mathrm{C}, \mathrm{C}-13), 145(\mathrm{C}, \mathrm{C}-2), 138(\mathrm{C}, \mathrm{C}-11), 131(\mathrm{C}, \mathrm{C}-10), 128(\mathrm{C}, \mathrm{C}-8), 121(\mathrm{C}, \mathrm{C}-9), 119(\mathrm{C}, \mathrm{C}-$ 12), 116(C, C-7), 105(C, C-4), 50(2C, C'-1, C'-5), 26(2C, C'-2, C'-4).MS: $\mathrm{M}^{+}$at m/z :283.27Anal.Calcd for $\mathrm{C}_{15} \mathrm{H}_{14} \mathrm{~N}_{4} \mathrm{O}_{2}: \mathrm{C}, 63.82 ; \mathrm{H}, 5.00 ; \mathrm{N}, 19.85 ; \mathrm{O}, 11.34$, Found; $\mathrm{C}, 63.90 ; \mathrm{H}, 5.12 ; \mathrm{N}, 20.00 ; \mathrm{O}, 11.29$

\section{6-imino-3,6-dihydrochromeno[7,6-d]imidazol-7-yl)(piperidin-1-yl)methanone(3i)}

IR $\left(\mathrm{KBr}, \mathrm{cm}^{-1}\right): 3385(-\mathrm{NH}), 1712(-\mathrm{C}=\mathrm{O}), 1600(-\mathrm{C}=\mathrm{C}), 1625(-\mathrm{N}=\mathrm{C}), 1095(-\mathrm{C}-\mathrm{O}) .{ }^{1} \mathrm{H}$ NMR $\left(\mathrm{CDCl}_{3}\right): \delta$ 12.50(s, H, -NH, imidazole), 9.50(s, -H, -N=H), 8.60(s, H, C-8), 8.20(s, H, C-2), 7.30(s, H, C-9), 7.00(s, $\mathrm{H}, \mathrm{C}-4), 4.00\left(\mathrm{t}, 4 \mathrm{H},-2 \mathrm{xCH}_{2}\right.$, piperidinyl $), 2.10\left(\mathrm{t}, 4 \mathrm{H},-2 \mathrm{xCH}_{2}\right.$, piperidinyl $), 1.6(\mathrm{~m}, 2 \mathrm{H}$, piperidinyl $) .{ }^{13} \mathrm{C}$ NMR (CDCl $\left.{ }_{3}\right): \delta 164(\mathrm{C}, \mathrm{CO}), 161(\mathrm{C}, \mathrm{C}=\mathrm{NH}), 150(\mathrm{C}, \mathrm{C}-13), 144(\mathrm{C}, \mathrm{C}-2), 139(\mathrm{C}, \mathrm{C}-11), 132(\mathrm{C}, \mathrm{C}-10)$, 130(C, C-8), 121(C, C-9), 118(C, C-12), 115(C, C-7), 101(C, C-4), 50(2C, C'-2, C'-6), 30(2C, C'-2, C'4), 25(C, C'-4).MS: $\mathrm{M}^{+}$at $\mathrm{m} / \mathrm{z}: 297.40$ Anal.Calcd for $\mathrm{C}_{16} \mathrm{H}_{16} \mathrm{~N}_{4} \mathrm{O}_{2}: \mathrm{C}, 64.85 ; \mathrm{H}, 5.44 ; \mathrm{N}, 18.91 ; \mathrm{O}, 10.80$, Found; C, 64.90; H, 5.40; N, 18.98; O, 10.71

6-imino-N-phenyl-3, 6-dihydrochromeno [7,6-d] imidazole-7-carboxamide(3j)

IR $\left(\mathrm{KBr}, \mathrm{cm}^{-1}\right)$ : 3410(-NH), $1725(-\mathrm{C}=\mathrm{O}), 1625(-\mathrm{C}=\mathrm{C}), 1200(-\mathrm{C}-\mathrm{O}) .{ }^{1} \mathrm{H}$ NMR $\left(\mathrm{CDCl}_{3}\right): \delta 12.50(\mathrm{~s}, \mathrm{H},-\mathrm{NH}$, imidazole), $11.10(\mathrm{~s},-\mathrm{H},-\mathrm{N}-\mathrm{H}), 9.45(\mathrm{~s}, \mathrm{H},-\mathrm{C}=\mathrm{NH}), 8.75(\mathrm{~s}, \mathrm{H}, \mathrm{C}-8), 8.21(\mathrm{~s}, \mathrm{H}, \mathrm{C}-2), 8.0\left(\mathrm{~d}, 2 \mathrm{H}, \mathrm{C}^{\prime}-2\right.$, C'-

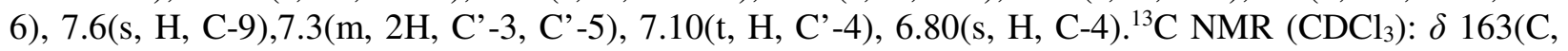
$\mathrm{CO}), 161(\mathrm{C}, \mathrm{C}=\mathrm{NH}), 150(\mathrm{C}, \mathrm{C}-13), 142(\mathrm{C}, \mathrm{C}-2), 140(\mathrm{C}, \mathrm{C}-11), 137\left(\mathrm{C}, \mathrm{C}^{\prime}-1\right), 132(\mathrm{C}, \mathrm{C}-10), 130\left(2 \mathrm{C}, \mathrm{C}^{\prime}-\right.$ 3, C'-5), 129(C, C-8), 126(C, C'-4), 123(2C, C'-2, C'-6), 119(C, C-7), 117(C, C-9), 116(C, C-12), 103(C, C-4).MS: $\mathrm{M}^{+}$at $\mathrm{m} / \mathrm{z}: 305.35$ Anal.Calcd for $\mathrm{C}_{17} \mathrm{H}_{12} \mathrm{~N}_{4} \mathrm{O}_{2}$ : C, 67.10; H, 3.97; N, 18.41; O, 10.52, Found; C, 67.20; H, 4.10; N, 18.32; O, 10.50

\section{N-(4-chlorophenyl)-6-imino-3,6-dihydrochromeno[7,6-d]imidazole-7-carboxamide(3k)}

IR $\left(\mathrm{KBr}, \mathrm{cm}^{-1}\right)$ : $3351(-\mathrm{NH}), 1769(-\mathrm{C}=\mathrm{O}), 1599(-\mathrm{C}=\mathrm{C}), 1155(-\mathrm{C}-\mathrm{O}), 780(\mathrm{C}-\mathrm{Cl}) .{ }^{1} \mathrm{H}$ NMR $\left(\mathrm{CDCl}_{3}\right): \delta$ 12.28(s, H, -NH, imidazole), 11.00(s, -H, $-\mathrm{N}-\mathrm{H}), 9.34(\mathrm{~s}, \mathrm{H},-\mathrm{C}=\mathrm{NH}), 8.67(\mathrm{~s}, \mathrm{H}, \mathrm{C}-8), 8.33(\mathrm{~s}, \mathrm{H}, \mathrm{C}-2)$,

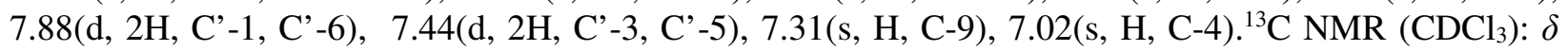
165(C, CO), $161(\mathrm{C}, \mathrm{C}=\mathrm{NH}), 151(\mathrm{C}, \mathrm{C}-13), 145(\mathrm{C}, \mathrm{C}-2), 138(\mathrm{C}, \mathrm{C}-11), 136\left(\mathrm{C}, \mathrm{C}^{\prime}-1\right), 135\left(\mathrm{C}, \mathrm{C}^{\prime}-4\right)$, 127(C, C-8), 133(C, C-10), 130(2C, C'-3, C'-5), 128(C, C-8), 126(C, C'-4), 122(2C, C'-2, C'-6), 120(C, C-7), 118(C, C-9), 115(C, C-12), 102(C, C-4).MS: $\mathrm{M}^{+}$at $\mathrm{m} / \mathrm{z}: 339.70$. Anal.Calcd for $\mathrm{C}_{17} \mathrm{H}_{11} \mathrm{ClN}_{4} \mathrm{O}_{2}$ : C, 60.28; H, 3.27; Cl, 10.47; N, 16.54; O, 9.45, Found; C, 60.30; H, 3.35; Cl, 10.55; N, 16.40; O, 9.48 
N-(4-fluorophenyl)-6-imino-3,6-dihydrochromeno[7,6-d]imidazole-7-carboxamide(31)

IR $\left(\mathrm{KBr}, \mathrm{cm}^{-1}\right): 3313(-\mathrm{NH}), 1687(-\mathrm{C}=\mathrm{O}), 1634(-\mathrm{C}=\mathrm{C}), 1188(-\mathrm{C}-\mathrm{O}), 1054(\mathrm{C}-\mathrm{F}) .{ }^{1} \mathrm{H}$ NMR $\left(\mathrm{CDCl}_{3}\right): \delta$ 12.30(s, H, -NH, imidazole), 11.05(s, -H, $-\mathrm{N}-\mathrm{H}), 9.41(\mathrm{~s}, \mathrm{H},-\mathrm{C}=\mathrm{NH}), 8.61(\mathrm{~s}, \mathrm{H}, \mathrm{C}-8), 8.21(\mathrm{~s}, \mathrm{H}, \mathrm{C}-2)$, 7.75(d, 2H, C'-1,C'-6), 7.30(d, 2H, C'-3, C'-5), 7.25(s, H, C-9), 7.00(s, H, C-4) ${ }^{13} \mathrm{C}^{\mathrm{NMR}}\left(\mathrm{CDCl}_{3}\right): \delta$ 165(C, CO), 162(C, C'-4), 158(C, C=NH), 151(C, C-13), 143(C, C-2), 139(C, C-11), 136(C, C'-1), 126(C, C-8), 132(C, C-10), 129(2C, C'-3, C'-5), 118(2C, C'-2, C'-6), 116(C, C-7), 115(C, C-9), 112(C, C-12), 101(C,C-4).MS: $\mathrm{M}^{+}$at $\mathrm{m} / \mathrm{z}$ :323.30.Anal.Calcd for $\mathrm{C}_{17} \mathrm{H}_{11} \mathrm{FN}_{4} \mathrm{O}_{2}: \mathrm{C}, 63.35 ; \mathrm{H}, 3.44 ; \mathrm{F}, 5.89$; N, 17.38; O, 9.93, Found; 63.40; H, 3.54; F, 5.92; N, 17.20; O, 9.85

\section{N-(4-hydroxyphenyl)-6-imino-3, 6-dihydrochromeno [7,6-d] imidazole-7-carboxamide (3m)}

IR $\left(\mathrm{KBr}, \mathrm{cm}^{-1}\right): 3418(-\mathrm{OH}), 3351(-\mathrm{NH}), 1745(-\mathrm{C}=\mathrm{O}), 1588(-\mathrm{C}=\mathrm{C}), 1155(-\mathrm{C}-\mathrm{O}){ }^{1}{ }^{1} \mathrm{H}$ NMR $\left(\mathrm{CDCl}_{3}\right): \delta$ 12.36(s, H, -NH, imidazole), 11.11(s, -H, -N-H), 9.70(s, H,-OH), 9.40(s, H, -C=NH), 8.71(s, H, C-8), 8.21(s, H, C-2), 7.50(d, 2H, C'-1, C'-6), 7.30(s, H, C-9), 7.00(s, H, C-4), 6.80(d, 2H, C'-3, C'-5). ${ }^{13} \mathrm{C}$ NMR $\left(\mathrm{CDCl}_{3}\right): \delta 163(\mathrm{C}, \mathrm{CO}), 160(\mathrm{C}, \mathrm{C}=\mathrm{NH}), 154\left(\mathrm{C}, \mathrm{C}^{\prime}-4\right), 150(\mathrm{C}, \mathrm{C}-13), 145(\mathrm{C}, \mathrm{C}-2), 139(\mathrm{C}, \mathrm{C}-11)$, 131(C, C'-1), 127(C, C-8), 134(C, C-10), 118(2C, C'-3, C'-5), 129(C, C-8), 126(C, C'-4), 125(2C, C'-2, C'-6), 119(C, C-7), 120(C, C-9), 121(C, C-12), 103(C, C-4).MS: $\mathrm{M}^{+}$at $\mathrm{m} / \mathrm{z}: 321.27$. Anal.Calcd for $\mathrm{C}_{17} \mathrm{H}_{12} \mathrm{~N}_{4} \mathrm{O}_{3}$ : C, 63.75; H, 3.78; N, 17.49; O, 14.99, Found; C, 63.81; H, 3.65; N, 17.55; O, 15.10

\section{N-benzyl-6-imino-3, 6-dihydrochromeno [7, 6-d] imidazole-7-carboxamide (3n)}

IR $\left(\mathrm{KBr}, \mathrm{cm}^{-1}\right): 3329(-\mathrm{NH}), 1733(-\mathrm{C}=\mathrm{O}), 1585(-\mathrm{C}=\mathrm{C}), 1100(-\mathrm{C}-\mathrm{O}) .{ }^{1} \mathrm{H}$ NMR $\left(\mathrm{CDCl}_{3}\right): \delta 12.18(\mathrm{~s}, \mathrm{H},-$ $\mathrm{NH}$, imidazole), 9.29(s, -H, -N=H), 8.80(s, H,-NH, amide), 8.46(s, H, C-8), 8.18(s, H, C-2), 7.25(s, H, C9), 7.42(d, 2H, C'-6, C'-2), 7.28(t, H, C'-4), 7.19(d, 2H, C'-5, C'-3), 6.81(s, H, C-4), 5.2(s, 2H, $-\mathrm{CH}_{2}-$ $\mathrm{NH}) .{ }^{13} \mathrm{C}$ NMR $\left(\mathrm{CDCl}_{3}\right): \delta 163(\mathrm{C}, \mathrm{C}-6), 160(\mathrm{C},-\mathrm{CO}), 151(\mathrm{C}, \mathrm{C}-13), 144(\mathrm{C}, \mathrm{C}-2), 140\left(\mathrm{C}, \mathrm{C}^{\prime}-1\right), 137(\mathrm{C}$, C-11), 132(C, C-10), 129(2C, C'-5, C'-3), 125(2C, C'-2, C'-6), 123(2C, C-8, C'-4), 119(C, C-9), 117(C, C-12), 15(C, C-7), 105(C, C-4), 45(C,- $\left.\mathrm{CH}_{2}\right)$.MS: $\mathrm{M}^{+}$at $\mathrm{m} / \mathrm{z}: 319.25$.Anal.Calcd for $\mathrm{C}_{18} \mathrm{H}_{14} \mathrm{~N}_{4} \mathrm{O}_{2}: \mathrm{C}$, $67.91 ; \mathrm{H}, 4.43 ; \mathrm{N}, 17.60 ; \mathrm{O}, 10.05$, Found; C, 67.80; H, 4.50; N, 17.55; O, 10.15

\section{(S)-6-imino-N-(1-phenylethyl)-3,6-dihydrochromeno[7,6-d]imidazole-7-carboxamide(3o)}

IR $\left(\mathrm{KBr}, \mathrm{cm}^{-1}\right)$ : 3341(-NH), $1742(-\mathrm{C}=\mathrm{O}), 1566(-\mathrm{C}=\mathrm{C}), 1115(-\mathrm{C}-\mathrm{O}) .{ }^{1} \mathrm{H}$ NMR $\left(\mathrm{CDCl}_{3}\right): \delta 12.35(\mathrm{~s}, \mathrm{H},-$ $\mathrm{NH}$, imidazole), 9.35(s, -H,-N=H), 8.5(s, H, -NH, amide), 8.6(s, H, C-8), 8.20(s, H, C-2), 7.30(s, H, C-9), 7.5(d, 2H, C'-6, C'-2), 7.1(d, 2H, C'-5, C'-3), 6.9(s, H, C-4), 6.7(t, H, C'-4), 5.2(q, H, -CH-NH), 1.45(d, $3 \mathrm{H}, \mathrm{Me}){ }^{13} \mathrm{C}$ NMR $\left(\mathrm{CDCl}_{3}\right): \delta 165\left(\mathrm{C}, \mathrm{C}^{\prime}-1\right), 162(\mathrm{C}, \mathrm{C}-6), 160(\mathrm{C},-\mathrm{CO}), 152(\mathrm{C}, \mathrm{C}-13), 145(\mathrm{C}, \mathrm{C}-2)$, 136(C, C-11), 133(C, C-10), 130(2C, C'-5, C'-3) , 127(2C, C'-2, C'-6), 126(2C, C-8, C'-4), 118(C, C-9), 116(C, C-12), 114(C, C-7), 103(C, C-4), 55(C, -CH), 22(C, -Me).MS: $\mathrm{M}^{+}$at m/z :333.35. Anal.Calcd for $\mathrm{C}_{19} \mathrm{H}_{16} \mathrm{~N}_{4} \mathrm{O}_{2}$ : C, 68.66; H, 4.85; N, 16.86; O, 9.63, Found; C, 68.72; H, 4.90; N, 16.90; O, 9.51

6-imino-N-(1-(4-methoxyphenyl)ethyl)-3,6-dihydrochromeno[7,6-d]imidazole-7-carboxamide(3p) IR $\left(\mathrm{KBr}, \mathrm{cm}^{-1}\right): 3312(-\mathrm{NH}), 1754(-\mathrm{C}=\mathrm{O}), 1499(-\mathrm{C}=\mathrm{C}), 1099(-\mathrm{C}-\mathrm{O}) .{ }^{1} \mathrm{H}$ NMR $\left(\mathrm{CDCl}_{3}\right): \delta 12.25(\mathrm{~s}, \mathrm{H}$, $\mathrm{NH}$, imidazole), 9.25(s, -H, -N=H), 8.7(s, H,-NH, amide), 8.5(s, H, C-8), 8.10(s, H, C-2), 7.40(s, H, C9), 7.2(d, 2H, C'-6, C'-2), 7.0(d, 2H, C'-5, C'-3), 6.7(s, H, C-4), 5.0(q, H, -CH-NH), 3.9(s, 3H,-OMe), $1.5(\mathrm{~d}, 3 \mathrm{H}, \mathrm{Me}) .{ }^{13} \mathrm{C}$ NMR $\left(\mathrm{CDCl}_{3}\right): \delta 161(\mathrm{C}, \mathrm{C}-6), 159(\mathrm{C},-\mathrm{CO}), 155\left(\mathrm{C}, \mathrm{C}^{\prime}-4\right), 149(\mathrm{C}, \mathrm{C}-13), 148\left(\mathrm{C}, \mathrm{C}^{\prime}-\right.$ 5), 143(C, C-2), 138(C, C-11), 132(C, C-10), 130(C, C'-1), 129(2C, C'-2, C'-6), 115(2C, C'-5, C'-3), 127(C, C-8), 117(C, C-9), 115(C, C-12), 114(C, C-7), 103(C, C-4), 58(C,- OMe), 50(C, -CH), 25(C, Me).MS: $\mathrm{M}^{+}$at $\mathrm{m} / \mathrm{z}$ :363.35.Anal.Calcd for $\mathrm{C}_{20} \mathrm{H}_{18} \mathrm{~N}_{4} \mathrm{O}_{3}: \mathrm{C}, 66.29 ; \mathrm{H}, 5.01 ; \mathrm{N}, 15.46 ; \mathrm{O}, 13.25$, Found; $\mathrm{C}$, $66.31 ; \mathrm{H}, 5.10 ; \mathrm{N}, 15.50 ; \mathrm{O}, 13.14$

\section{$\mathrm{N}$-(2, 5-dimethoxybenzyl)-6-imino-3, 6-dihydrochromeno [7, 6-d] imidazole-7-carboxamide (3q)} IR (KBr, cm $\left.{ }^{-1}\right): 3295(-\mathrm{NH}), 1745(-\mathrm{C}=\mathrm{O}), 1595(-\mathrm{C}=\mathrm{C}), 1180(-\mathrm{C}-\mathrm{O}) .{ }^{1} \mathrm{H}$ NMR $\left(\mathrm{CDCl}_{3}\right): \delta 12.00(\mathrm{~s}, \mathrm{H},-$ $\mathrm{NH}$, imidazole), 9.55(s, -H, -N=H), 9.00(s, H, -NH, amide), 8.60(s, H, C-8), 8.20(s, H, C-2), 7.45(s, H, C-9), 7.2(s, H, C'-6), 7.0(m, 3H, C'-5, C'-4, C'-3), 6.9(s, H, C-4), 4.5(s, 2H, - $\left.\mathrm{CH}_{2}\right), 4.0(\mathrm{~s}, 6 \mathrm{H},-$ 
$2 \mathrm{xOMe}) .{ }^{13} \mathrm{C}$ NMR $\left(\mathrm{CDCl}_{3}\right): \delta$ 163(C, C-6), $160(\mathrm{C}, \mathrm{CO}), 150(\mathrm{C}, \mathrm{C}-13), 148\left(\mathrm{C}, \mathrm{C}^{\prime}-5\right), 145\left(\mathrm{C}, \mathrm{C}^{\prime}-2\right)$, 142(C, C-2), 130(C, C'-1), 116(2C, C'-6, C'-3), 145(C, C-2), 137(C, C-11), 131(C, C-10), 125(C,C-8), 119(C, C-9), 116(C, C-12),114(C, C-7), 112(C, C'-3), 102(C, C-4), 60(2C,-OMe), 40(C, -CH2).MS: ${ }^{+}$at $\mathrm{m} / \mathrm{z}$ :379.40 Anal.Calcd for $\mathrm{C}_{20} \mathrm{H}_{18} \mathrm{~N}_{4} \mathrm{O}_{4}$ : C, 63.48; H, 4.79; N, 14.81; O, 16.91, Found; C, 63.55; H, 4.90; $\mathrm{N}, 14.75 ; \mathrm{O}, 16.80$

\section{6-imino- $\mathrm{N}$-(pyridin-2-yl)-3,6-dihydrochromeno [7,6-d]imidazole-7-carboxamide(3r)}

IR $\left(\mathrm{KBr}, \mathrm{cm}^{-1}\right): 3350(-\mathrm{NH}), 1755(-\mathrm{C}=\mathrm{O}), 1652(-\mathrm{C}=\mathrm{C}), 1100(-\mathrm{C}-\mathrm{O}) .{ }^{1} \mathrm{H}$ NMR $\left(\mathrm{CDCl}_{3}\right): \delta 12.25(\mathrm{~s}, \mathrm{H},-$ $\mathrm{NH}$, imidazole), 10.65(s, H, amide), 9.35(s, -H, -N=H), 8.68(s, H, C-8), 8.25(s, H, C-2), 8.2(d, H, C'-6),

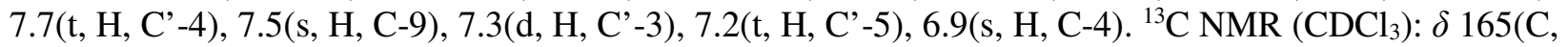
C-6), 162 (C, -CO), 155(C, C-13), 150(C, C'-2), 148(C, C'-4), 151(C, C'-6), 145(C, C-2), 143(C, C-11), 135(C, C-10), 128(C, C-8), 125(C, C'-5), 119(C, C-9), 116(C, C-12), 114(C, C-7), 112(C, C'-3), 102(C, C-4).MS: $\mathrm{M}^{+}$at $\mathrm{m} / \mathrm{z}: 306.30$ Anal.Calcd for $\mathrm{C}_{16} \mathrm{H}_{11} \mathrm{~N}_{5} \mathrm{O}_{2}$ : C, 62.95; H, 3.63; N, 22.94; O, 10.48, Found; C, $63.00 ; \mathrm{H}, 3.55 ; \mathrm{N}, 22.90 ; \mathrm{O}, 10.55$

\section{6-imino-N-(4-methylpyridin-2-yl)-3,6-dihydrochromeno[7,6-d]imidazole-7-carboxamide(3s)}

IR $\left(\mathrm{KBr}, \mathrm{cm}^{-1}\right)$ : 3420(-NH), 1751 (-C=O), 1640 (-C=C), 1125(-C-O). ${ }^{1} \mathrm{H}$ NMR $\left(\mathrm{CDCl}_{3}\right): \delta 12.00(\mathrm{~s}, \mathrm{H},-$ $\mathrm{NH}$, imidazole), 10.5(s, H, amide), 9.50(s, -H, -N=H), 8.55(s, H, C-8), 8.15(s, H, C-2), 7.9(d, H, C'-6), 7.5(s, H, C'-3), 7.2(s, H, C-5), 6.89(s, H, C -4), 2.5(s, 3H, -Me). ${ }^{13} \mathrm{C}$ NMR $\left(\mathrm{CDCl}_{3}\right): \delta 163\left(\mathrm{C}, \mathrm{C}^{\prime}-2\right), 162$ (C, -CO), 160(C, C-6), 158(C, C'-4), 155(C, C-13), 150(C, C-2), 144(C, C-11), 140(C, C'-6), 135(C, C10), 128(C, C-8), 125(C, C'-5), 119(C, C-9), 116(C, C-12), 114(C, C-7), 111(C, C'-3), 103(C, C-4), 25(C, -Me).MS: $\mathrm{M}^{+}$at $\mathrm{m} / \mathrm{z}: 320.30$ Anal.Calcd for $\mathrm{C}_{17} \mathrm{H}_{13} \mathrm{~N}_{5} \mathrm{O}_{2}: \mathrm{C}, 63.94 ; \mathrm{H}, 4.10 ; \mathrm{N}, 21.93 ; \mathrm{O}, 10.02$, Found; C, 64.00; H, 4.15; N, 22.00; O, 10.00

\section{6-imino-N-(thiazol-2-yl)-3,6-dihydrochromeno[7,6-d]imidazole-7-carboxamide (3t)}

IR $\left(\mathrm{KBr}, \mathrm{cm}^{-1}\right): 3500(-\mathrm{NH}), 1758(-\mathrm{C}=\mathrm{O}), 1575(-\mathrm{C}=\mathrm{C}), 1088(-\mathrm{C}-\mathrm{O}), 635(\mathrm{C}-\mathrm{S}) .{ }^{1} \mathrm{H}$ NMR $\left(\mathrm{CDCl}_{3}\right): \delta$ 12.5(s, H, amide), 12.00 (s, H, -NH, imidazole), 9.50(s, -H,-N=H), 8.60(s, H, C-8), 8.25(s, H, C-2), 8.0(d, $\left.\mathrm{H}, \mathrm{C}^{\prime}-5\right), 7.8\left(\mathrm{~d}, \mathrm{H}, \mathrm{C}^{\prime}-4\right), 7.5(\mathrm{~s}, \mathrm{H}, \mathrm{C}-9), 7.0(\mathrm{~s}, \mathrm{H}, \mathrm{C}-4) .{ }^{13} \mathrm{C}$ NMR $\left(\mathrm{CDCl}_{3}\right): \delta 165\left(\mathrm{C}, \mathrm{C}^{\prime}-2\right), 162(\mathrm{C}, \mathrm{C}-6)$, 160 (C, -CO), 151(C, C-13), 148(C, C-2), 142(C, C-11), 133(C, C-10), 130(C, C'-5), 126(C, C-8), 119(C, C-9), 117(C, C-12), 115(C, C-7), 111(C, C'-4), 104(C, C-4).MS: $\mathrm{M}^{+}$at $\mathrm{m} / \mathrm{z}: 312.40$. Anal.Calcd for $\mathrm{C}_{14} \mathrm{H}_{9} \mathrm{~N}_{5} \mathrm{O}_{2} \mathrm{~S}: \mathrm{C}, 54.01 ; \mathrm{H}, 2.91 ; \mathrm{N}, 22.50 ; \mathrm{O}, 10.28 ; \mathrm{S}, 10.30$, Found; C, 54.10; H, 2.30; N, 22.65; O, $10.35 ; \mathrm{S}, 10.15$

\section{Docking Results}

Molecular docking studies of title compounds were performed with EGFR and docking score of these compounds were shown in Table-1. A purine based compound has been taken for comparison study as the standard reference drug ${ }^{46}$. However, docking results conferred that $4 \mathrm{~g}, 4 \mathrm{~m}, 4 \mathrm{n}, 4 \mathrm{q}, 4 \mathrm{r}, 4 \mathrm{j}, 4 \mathrm{i}, 4 \mathrm{p}, 4 \mathrm{~s}$ have shown highest docking score of -9.2 and $-9.1 \mathrm{kcal} / \mathrm{mol}, 4 \mathrm{~h}, 4 \mathrm{p}, 4 \mathrm{l}, 4 \mathrm{o}, 4 \mathrm{~d}$ have best docking of -8.8, -8.7, $8.6,-8.5,-8.0 \mathrm{kcal} / \mathrm{mol}$ whereas $4 \mathrm{~b}, 4 \mathrm{c}, 4 \mathrm{a}, 4 \mathrm{e}$, 4f have moderate docking score of $-7.9,-7.8,-7.6$ $\mathrm{kcal} / \mathrm{mol}$ respectively.

Table-2: Docking score, Binding energy, the Binding affinity of compounds with binding pocket of synthesized molecules against epidermal growth factor (PDBID: 3POZ).

\begin{tabular}{c|c|c|c|c}
\hline S. No. & Ligand & $\begin{array}{c}\text { Autodock score } \\
(\mathrm{S})\end{array}$ & $\begin{array}{c}\text { Binding energy } \\
(\mathrm{kcal} / \mathrm{mol})\end{array}$ & $\begin{array}{c}\text { Binding affinity } \\
(\mathrm{PKi})\end{array}$ \\
\hline 1 & $4 \mathrm{~g}$ & -9.2 & -16.3 & 7.1 \\
\hline 2 & $4 \mathrm{~m}$ & -9.2 & -14.4 & 9.2 \\
\hline 3 & $4 \mathrm{n}$ & -9.2 & -16.0 & 8.0 \\
\hline 4 & $4 \mathrm{q}$ & -9.2 & -10.6 & 7.7 \\
\hline
\end{tabular}


RASĀYAN $J$. Chem.

Vol. 10 | No. 4 |1194-1212 | October - December | 2017

\begin{tabular}{c|c|c|c|c}
\hline 5 & $4 \mathrm{r}$ & -9.2 & -9.9 & 7.8 \\
\hline 6 & $4 \mathrm{j}$ & -9.1 & -9.5 & 7.0 \\
\hline 7 & $4 \mathrm{i}$ & -9.0 & -12.5 & 7.2 \\
\hline 8 & $4 \mathrm{p}$ & -9.0 & -12.1 & 7.6 \\
\hline 9 & $4 \mathrm{~s}$ & -9.0 & -19.0 & 7.5 \\
\hline 10 & $4 \mathrm{t}$ & -8.8 & -12.7 & 7.6 \\
\hline 11 & $4 \mathrm{~h}$ & -8.7 & -17.1 & 7.9 \\
\hline 12 & $4 \mathrm{p}$ & -8.6 & -11.6 & 7.2 \\
\hline 13 & $4 \mathrm{l}$ & -8.5 & -12.8 & 8.4 \\
\hline 14 & $4 \mathrm{o}$ & -8.5 & -26.4 & 8.7 \\
\hline 15 & $4 \mathrm{~d}$ & -8.2 & -16.5 & 7.9 \\
\hline 16 & $4 \mathrm{~b}$ & -7.9 & -17.7 & 6.4 \\
\hline 17 & $4 \mathrm{c}$ & -7.8 & -11.2 & 6.8 \\
\hline 18 & $4 \mathrm{a}$ & -7.6 & -13.6 & 6.2 \\
\hline 19 & $4 \mathrm{e}$ & -7.6 & -8.9 & 7.6 \\
\hline 20 & $4 \mathrm{f}$ & -7.6 & -18.2 & 7.1 \\
\hline 21 & Reference[46] & -10.2 & -42.9 & 12.7 \\
\hline
\end{tabular}

\section{Born interaction energies and binding affinities}

Ultimately, binding energy and binding affinity for the lead candidates and reference molecule were calculated with generalized Born/volume integral (GB/VI) module of MOE to prioritize identified promising lead molecules. Before calculating binding energies, each ligand-protein complex was energy minimized. Further, binding affinity was calculated for each and every hit molecule and reported in $\mathrm{Kcal} / \mathrm{Mol}$ unit. Promising lead candidates were selected based on good binding energy and binding affinity with equal or near to the reference molecule and possession of ligand conformations and binding interactions with residues of pocket (Table-2). 4o, 4s, 4f, 4b, 4h, 4d, 4n, 4g compounds have shown highest binding energies and formed binding interactions with binding pocket such Met793, Thr854, Asn842, Arg841, Asp855, Phe856, Gln355, Met266, Lys745 including non polar residues i. e., Leu718, Val726, Phe856.

Docking images of synthesized ligands with the target protein (PDB Id: 3POZ)

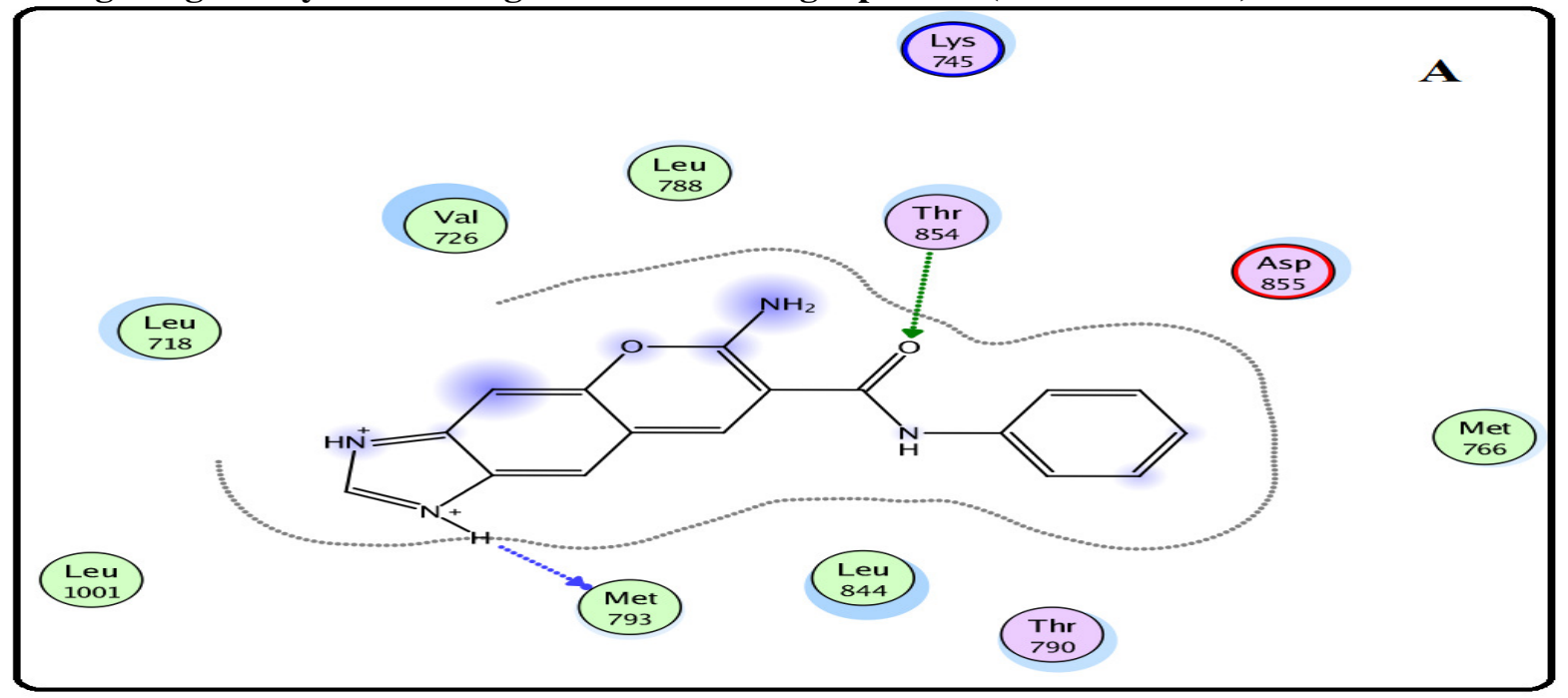


RASĀYAN J. Chem.

Vol. 10 | No. 4 |1194-1212 | October - December | 2017

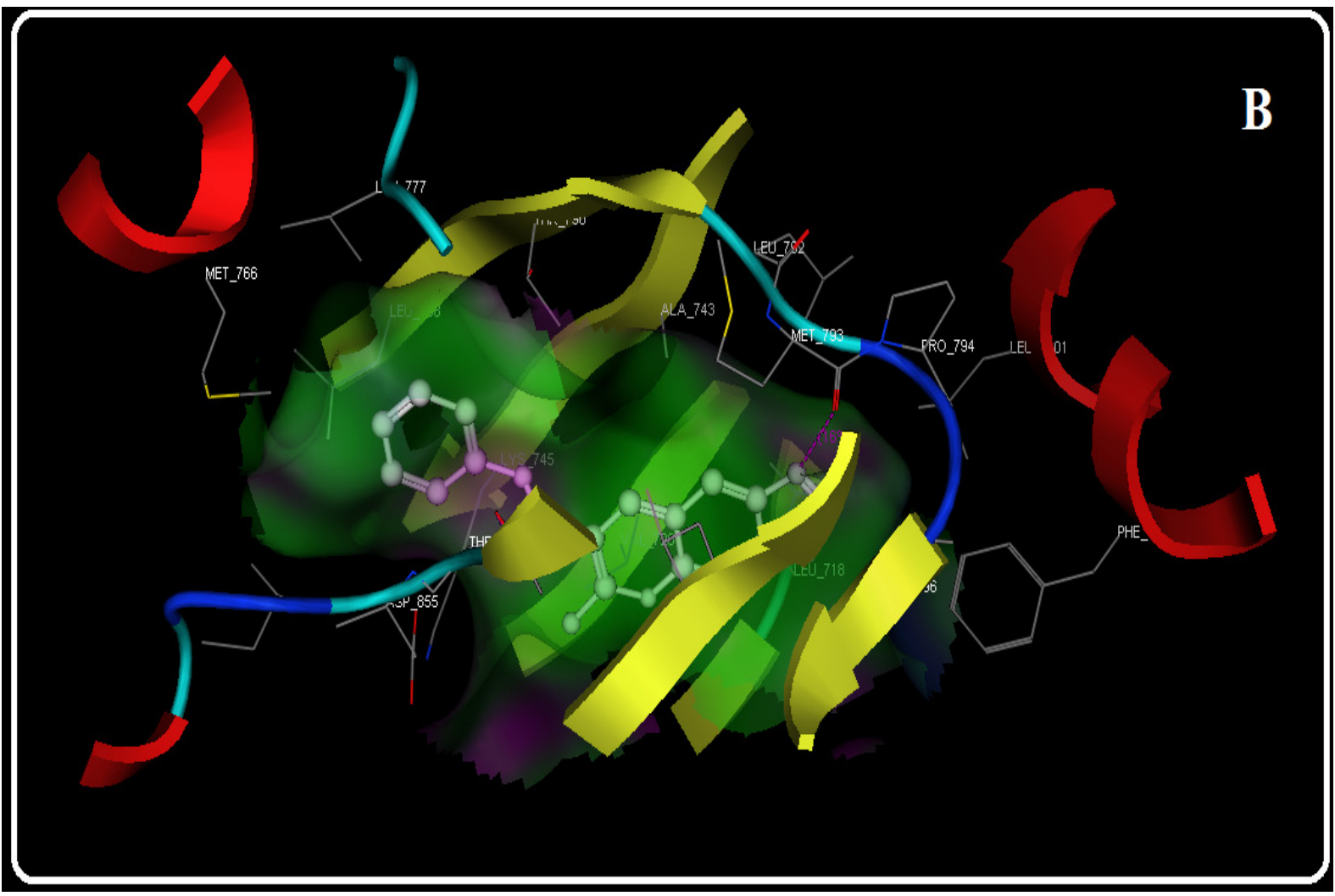

Fig.-3 : Docking images of compound $4 \mathrm{j}$ with the target protein(PBD Id: 3POZ).(A) docking pose of compound $4 \mathrm{j}$ $3 \mathrm{POZ}$ complex, where the ligand is depicted as chemical structure and protein is depicted in sphere model with an amino acid. (B) Hydrophobic pocket of 3POZ in green color and ligand is represented in ball and stick model.

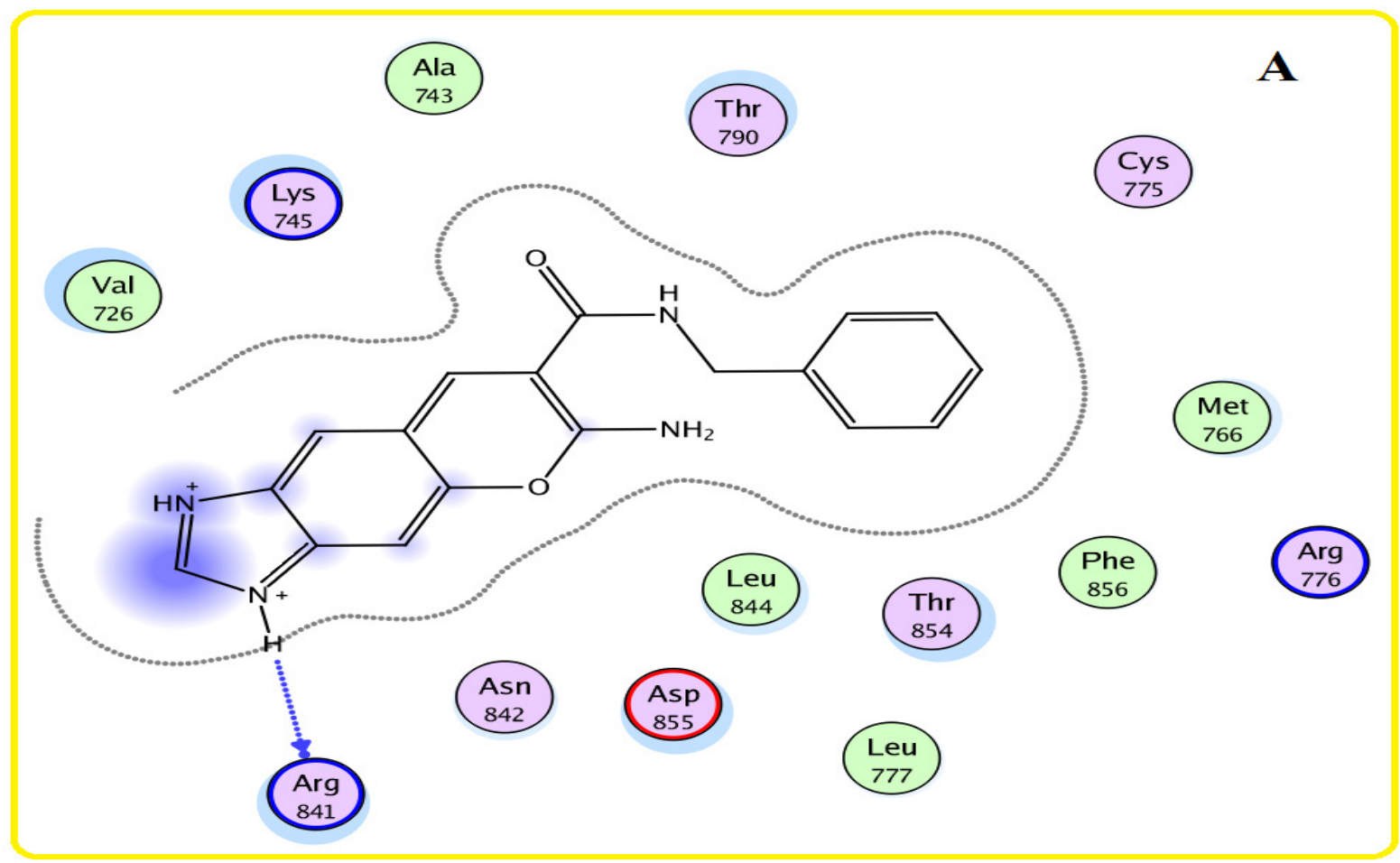


RASĀYAN J. Chem.

Vol. 10 | No. 4 |1194-1212 | October - December | 2017

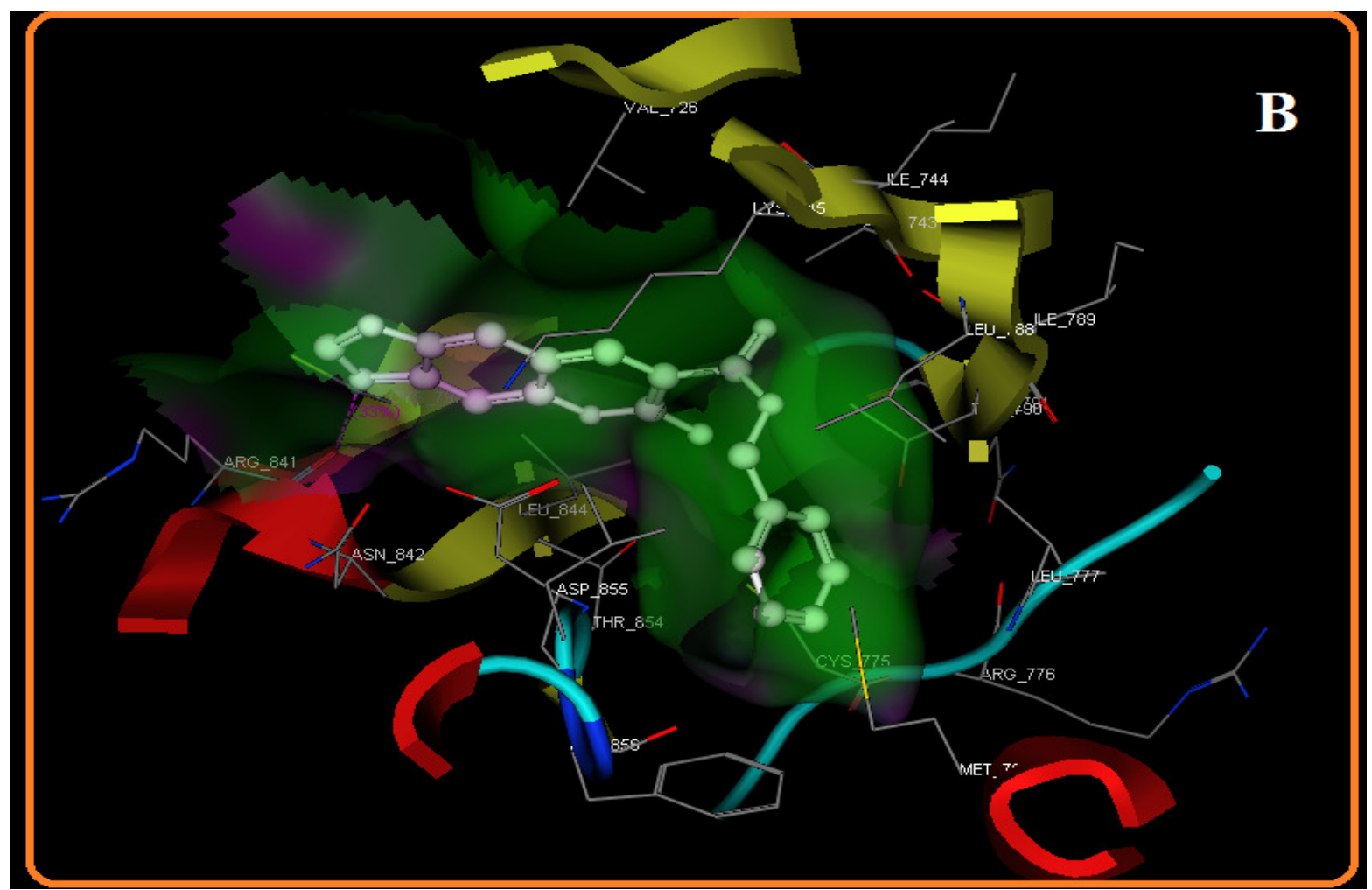

Fig.-4 : Docking images of compound $4 \mathrm{~m}$ with the target protein(PBD Id: 3POZ).(A) docking pose of compound $4 \mathrm{~m}$ - 3POZ complex, where the ligand is depicted as chemical structure and protein is depicted in sphere model with an amino acid. (B) Hydrophobic pocket of $3 \mathrm{POZ}$ in green color and ligand is represented in ball and stick model.

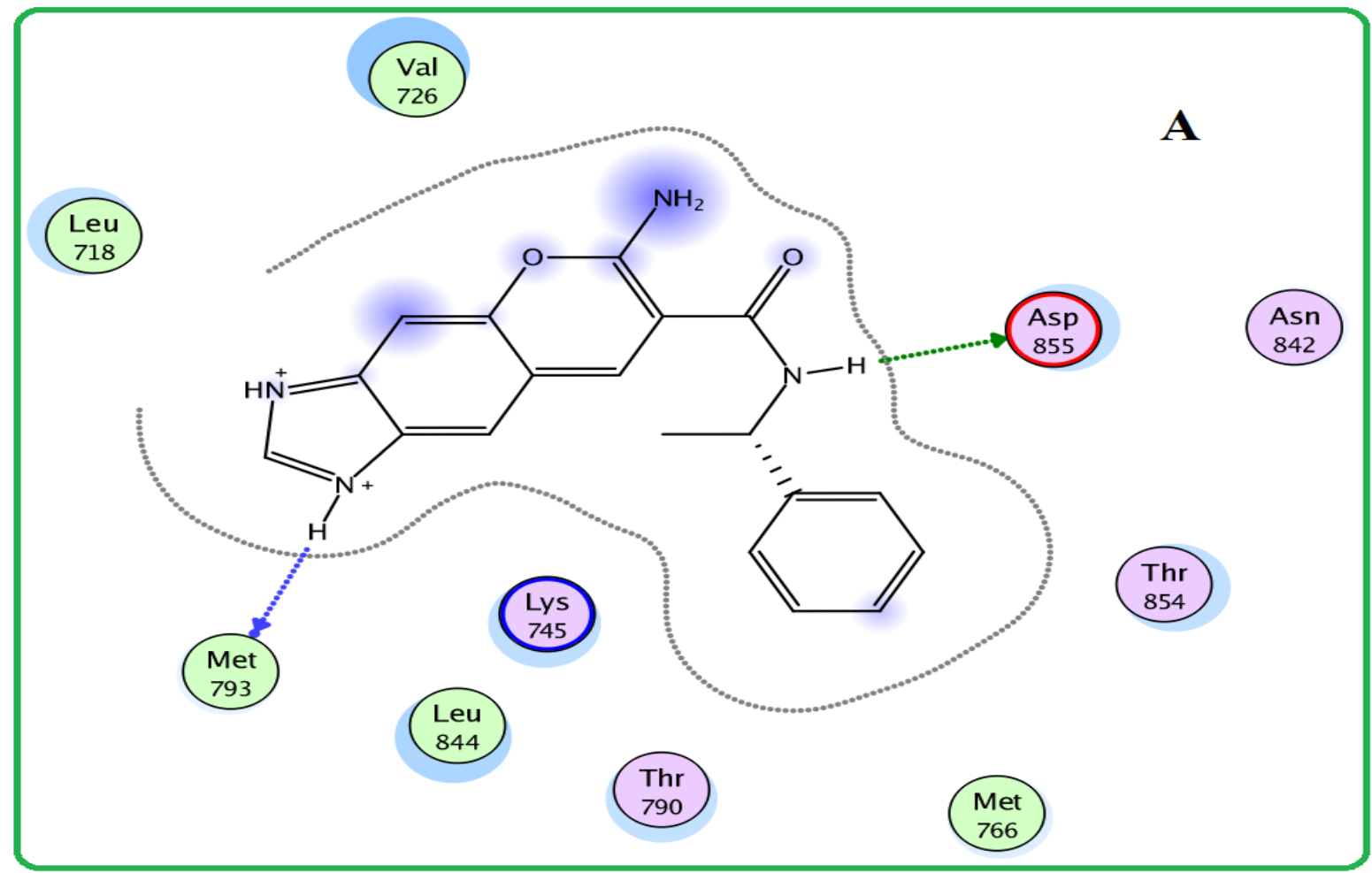


RASĀYAN J. Chem.

Vol. 10 | No. 4 |1194-1212 | October - December | 2017

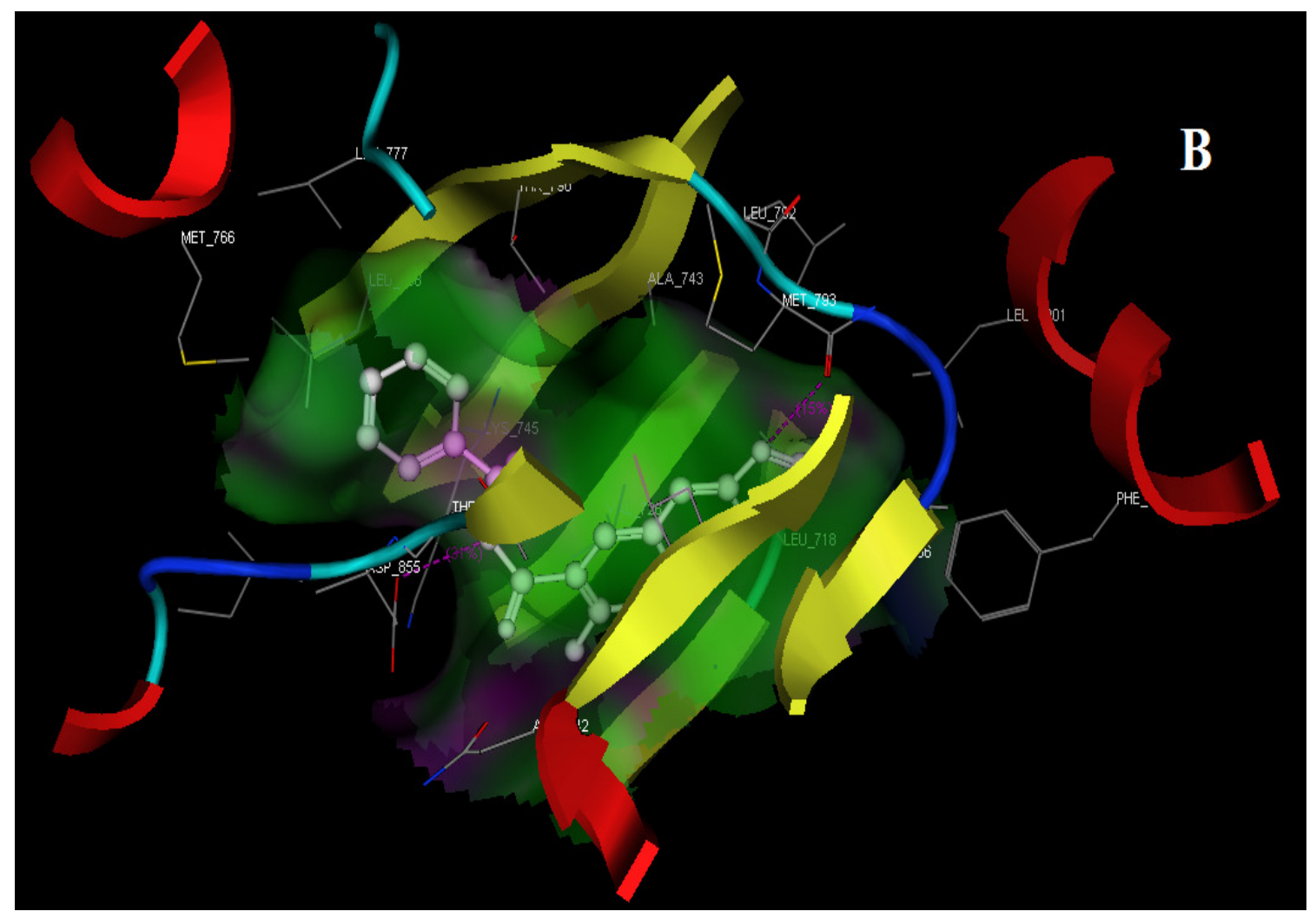

Fig.-5 : Docking images of compound $4 \mathrm{n}$ with the target protein(PBD Id: 3POZ).(A) docking pose of compound $4 \mathrm{n}$ - 3POZ complex, where the ligand is depicted as chemical structure and protein is depicted in sphere model with an amino acid. (B) Hydrophobic pocket of $3 \mathrm{POZ}$ in green color and ligand is represented in ball and stick model.

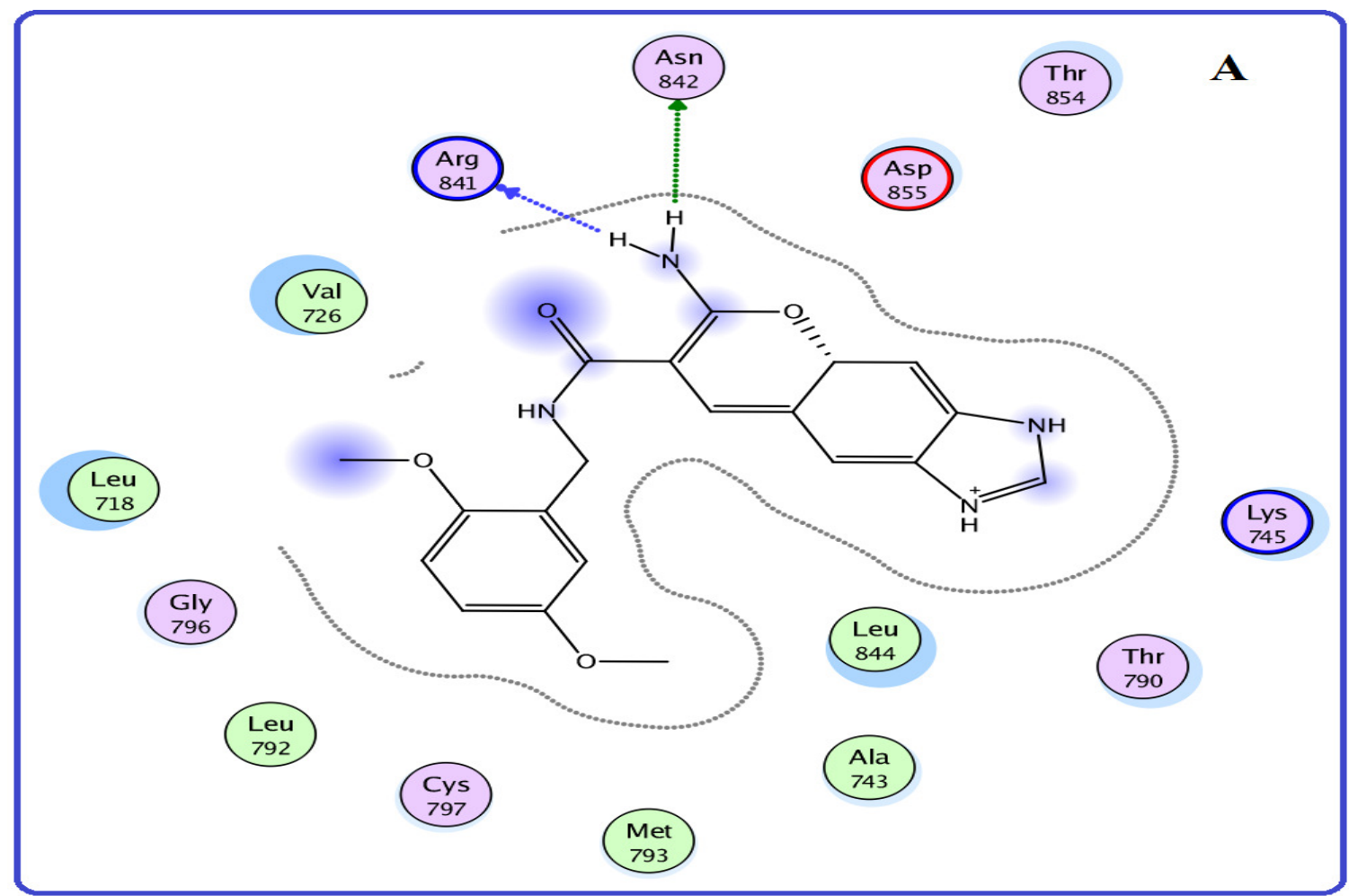


RASĀYAN J. Chem.

Vol. 10 | No. 4 |1194-1212 | October - December | 2017

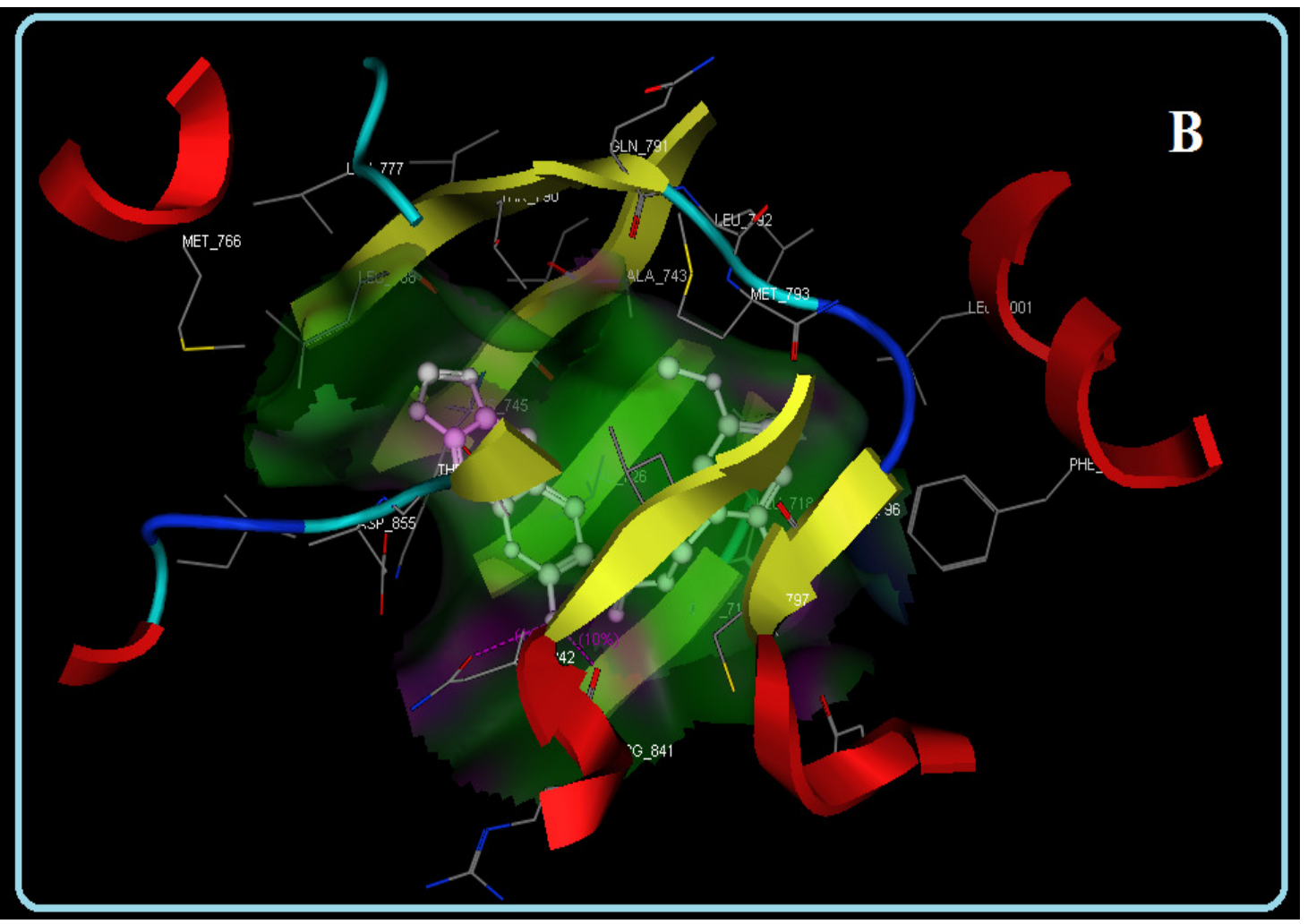

Fig.-6 : Docking images of compound 4s with the target protein(PBD Id: 3POZ).(A) docking pose of compound 4s $3 \mathrm{POZ}$ complex, where the ligand is depicted as chemical structure and protein is depicted in sphere model with an amino acid. (B) Hydrophobic pocket of 3POZ in green color and ligand is represented in ball and stick model.

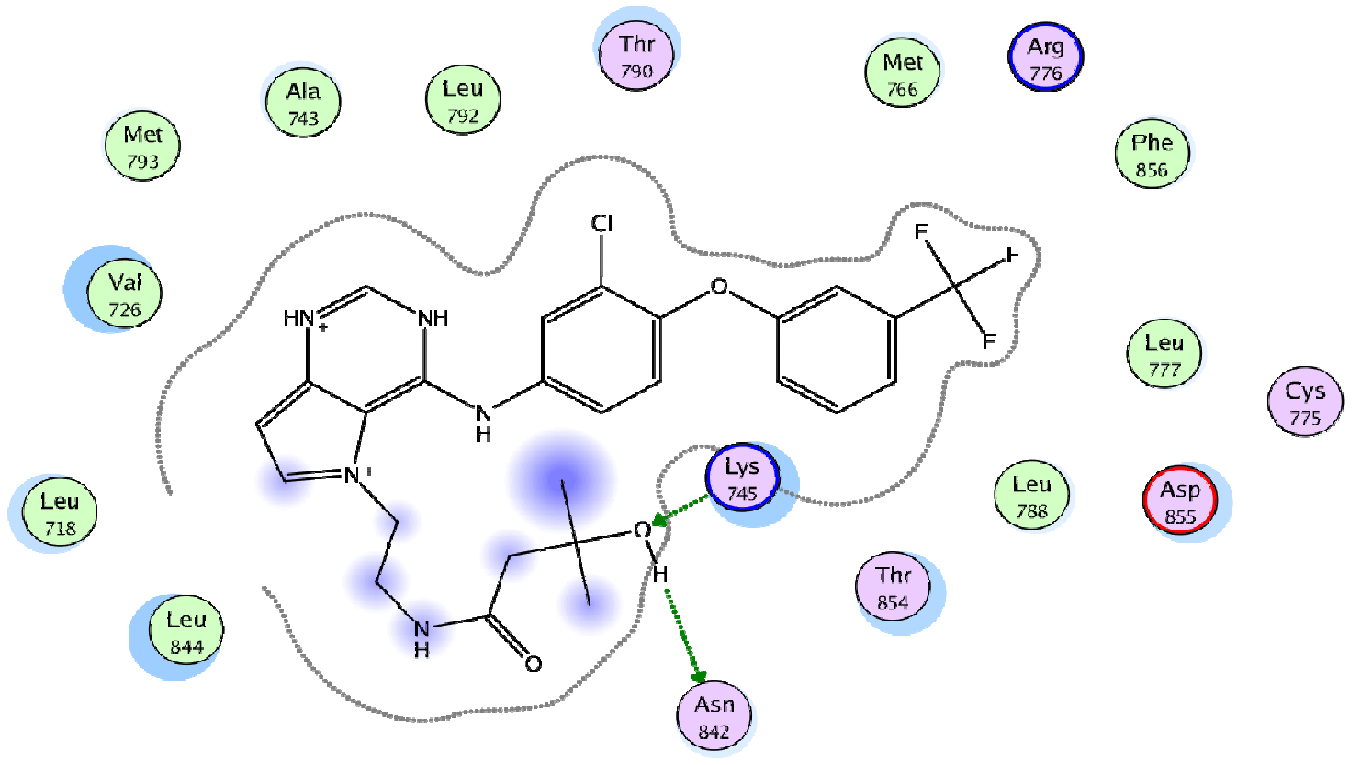

Arg 


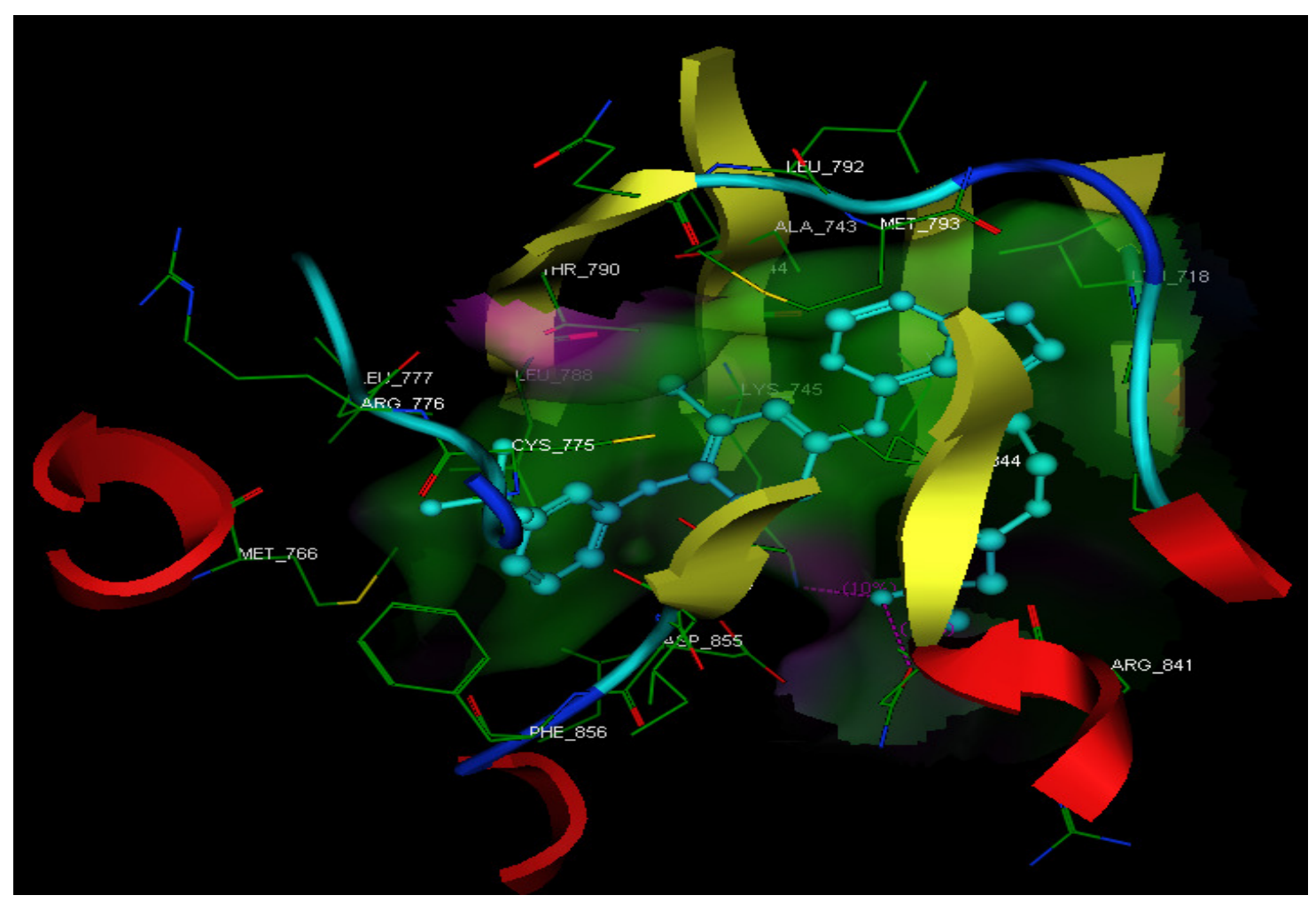

Fig.-7 : Docking images of reference standard with the target protein(PBD Id: 3POZ).(A) docking pose of compound $4 \mathrm{~s}-3 \mathrm{POZ}$ complex, where the ligand is depicted as chemical structure and protein is depicted in sphere model with amino acid. (B) Hydrophobic pocket of $3 \mathrm{POZ}$ in green color and ligand is represented in ball and stick model.

\section{CONCLUSION}

All the prepared compounds were structurally confirmed by spectral analysis. The chemical methods adopted were simple and chemists friendly. The compounds were screened for anti-lung cancer activity via computer aided docking method with software AUTODOCK VINA 4.0. Most of the synthesized compounds were shown good to moderate inhibition activity against the target protein $3 \mathrm{POZ}$ in terms of binding energy and docking pose with the amino acids. This study will be helpful for further study with respect to lung cancer disease.

\section{ACKNOWLEDGEMENT}

The authors thank K L University for constant encouragement during this research program. The authors expressed special gratitude to Dr. JVSK, Head, Dept. of Chemistry, KL University for providing the lab Facility and helping in the completion of work.

\section{REFERENCES}

1. M. Noolvi, S. Agrawal, H. Patel, A. Badiger, M. Gaba, A. Zambre, Arabian J. Chem., 8,715 (2015).

2. A. O. H. El-Nezhawy, H. I. El-Diwani, R. R Schmidt, Eur. J. of Org. Chem., 24, 4137 (2002).

3. R. Dua, S K. Sonwane, S K.Srivastava, S D. Srivastava. J. Chem. and Pharma. Res., 2(1), 415 (2010).

4. A. A. Selcen, S. Zencir, I. Zupko, G. Coban, B. Rethy, Z. Gunes, S. H. Topcu, J. Enz. inh Med. Chem.,24,844 (2009).

5. M. Singh,V.Tandon, Eur. J. Med. Chem., 46, 659 (2011).

6. H. A. Barker, R. D. Smyth, H. Weissbach, J. I. Toohey, J. N. Ladd, B. E. Volcani. J. Bio. Chem, 235(2),480 (1960). 
RASĀYAN J. Chem.

Vol. 10 | No. 4 |1194-1212 | October - December | 2017

7. G. Yadav, S. Ganguly, Eur. J. Med. Chem., 97,419 (2015).

8. H. M. Refat, Eur. J. Med. Chem., 45, 2949 (2010).

9. Y. Bansal, O. Silakari, Bioorg. \& Med. Chem.,20(21),6208 (2012).

10. H. M. Rafat, Eur. J. Med. Chem., 45(7), 2949(2010)

11. E. Lukowska-Chojnacka, P.Wińska, M.Wielechowska, M. Poprzeczko, M. Bretner, Bioorg. Med. Chem.,24(4), 735 (2016).

12. G. C. Cook, Parasitol Today, 6,133 (1990).

13. E. Redman, F. Whitelaw, A. Tait,C. Burgess,Y. Bartley, P.J. Skuce, F. Jackson, J.S. Gilleard, PLOS Negl. Trop. Dis.,9(2) (2015).

14. O.P. Agrawal, " Organic Chemistry Reactions and Reagents", Goel publishing house, New Delhi, 627.

15. H. Foks, D. Pancechowska-Ksepko, W. Kuzmierkiewicz, Z. Zwolska, E. Augustynowicz-Kopec, M. Janowiec, Chem. Heterocyclic Comp.,42,611 (2006).

16. A. Michele.Weidner-Wells, A. Kwasi. Ohemeng, V.N. Nguyen, Stephanie Fraga-Spano, Mark J. Macielag, M. Harvey, D. Werblood, D. Barbara. Foleno, G. C. Webb, F.J. Barrett, D.J. Hlasta. Bioorg. \& Med. Chem. Lett.,11(12), 1545 (2001).

17. A. Bali, M.Yogita Bansal, P. Sugumaran, J. S. Saggu, Balakumar, G. Kaur, G. Bansal, A. Sharma, M. Singh. Bioorg. \& Med.Chem.Lett.,15(17),3962 (2005).

18. M. M. Ramla, M. A. Omar, A.M. El-Khamry, H. I. El-Diwani. Bioorg. Med. Chem.,14(21), 7324 (2006).

19. A. Prasad, L. Thakurdesai, G. Sudhir Wadodkar, T. Chandrabhan Chopade, Pharma. online,1, 314 (2007).

20. K.F. Ansari, C. Lal. Eur. J. Med. Chem.,44, 2294 (2009).

21. Y. Ozkay, Y. Tunali, H. Karaca, I. Isikdag . Eur. J. Med. Chem.,45(8),3293 (2010).

22. M. M. Ramla et al., Bioorg. \& Med. Chem.,14,7324 (2006).

23. X.F. Han, X. He, M. Wang, D.Xu, L.P. Hao, A.H. Liang, J. Zhang, Z.M. Zhou, Eur. J. Med. Chem.,103, 473 (2015).

24. D. S. Salomon, R. Brandt, F. Ciardiello. Criti. Rev. in Oncol./Hema.,19,183 (1995).

25. N. Normanno, C. Bianco, L.Strizzi. curr. drug targ.,6, 243 (2005).

26. D.J. Leahy. Adv. in Prot. Chem.,68,1 (2004).

27. R.C Harris, E. Chung, Coffey RJ EGF receptor ligands. Exp. Cell Res., 284,2 (2003).

28. A. Merridee. Wouters, Isidore Rigoutsos, C.K. Chu, L.L.Feng, D.B. Sparrow, S.L. Dunwoodie, Prot. Sci.,14(4),1091 (2005).

29. P.S. Hammerman, P.A. Jänne, B.E. Johnson. Clin. Canc. Res.,15(24),7502 (2009).

30. N. Normanno., Endocrine-Related Cancer, 10,1(2003).

31. P. Carter, L. Presta, C. M. Gorman, J. B. Ridgway, D. Henner, W. L. Wong, A. M. Rowland, C. Kotts, M. E. Carver, H. M. Shepard, Proc.Natl. Acad. Sci., 89,4285 (1992).

32. K. Aertgeerts, R. Skene, J. Yano, Bi-Ching Sang, H. Zou, G. Snell, A. Jennings, K. Iwamoto, N. Habuka, A. Hirokawa, T. Ishikawa, T. Tanaka, H. Miki, Y. Ohta, and S. Sogabe. J..Bio. Chem.,286(21),18756 (2010).

33. P. Labute . J. Comp.Chem.,29,1693 (2008).

34. O. Trott, A. J. Olson. J. Comp.Chem., 31,455 (2010).

35. K. Wolf, L. PyRx, C\&EN; DeLano WL The PyMOL Molecular Graphics System DeLano Scientific, San Carlos; CA, USA (2012).

36. K. Reimer, F. Tiemann, Ber.der deuts.chemis. Gesellschaft,9,824 (1876) .

37. M. E. Jung, T. L. Lazarova. J. Org. Chem.,62,1553 (1997).

38. K. Wang, K. Nguyen, Y. Huang, A. Domling. J.Comb.Chem.,11(5),920 (2009).

39. A. A. Fadda, S. Bondock, R. Rabie, H. A. Etman. Turk .J. chem., 32,259 (2008).

40. K.E. Price, C. Larrivée-Aboussafy, B.M. Lillie, R. W. McLaughlin, J. Mustakis, K.W. Hettenbach, J.M. Hawkins, R. Vaidyanathan, Org.Lett.,11(9), 2003 (2009). 
RASĀYAN $J$. Chem.

Vol. 10 | No. 4 |1194-1212 | October - December | 2017

41. A. McChuskey, P. J. Robinson, T. Hill, J. L. Scott, J. K. Edwards. Tetra. Lett.,43(17), 3117 (2002)

42. D. M. Manidhar, K. Uma Maheswara Rao, N. Bakthavatchala Reddy, Ch. Syama Sundar, C. Suresh Reddy,J.Kor.Chem.Soc.,56(4),459 (2012).

43. A. D. Patel, M. S. Sharma, J. J. Vora, J. D. Joshi, J.Ind. Chem.Soc.,74, 287 (1997)

44. J. W. Wood, R.W. Bost, J.Am.Chem.Soc.,59,1721(1937).

45. A.Vilsmeier, A. Haack, Ber. der deuts. chemis. Gesellschaft,60, 119 (1927).

46. Y. Ohta, S.S. Bacus, A. Scott, Shell Prevention and treatment of cancer with lkb1 nonexpression (deletion or mutation). WO2010036928 A1(2010).

[RJC-1838/2017] 